\title{
Analysis of Reproductive Performance of Lactating Cows on Large Dairy Farms Using Machine Learning Algorithms
}

\author{
D. Z. Caraviello, ${ }^{*}$ K. A. Weigel, ${ }^{* 1}$ M. Craven,† D. Gianola, ${ }^{\star}$ N. B. Cook,‡ K. V. Nordlund,‡ \\ P. M. Fricke, ${ }^{\star}$ and M. C. Wiltbank* \\ *Department of Dairy Science, \\ †Department of Biostatistics and Medical Informatics, and \\ $\ddagger$ School of Veterinary Medicine University of Wisconsin, Madison 53706
}

\begin{abstract}
The fertility of lactating dairy cows is economically important, but the mean reproductive performance of Holstein cows has declined during the past 3 decades. Traits such as first-service conception rate and pregnancy status at $150 \mathrm{~d}$ in milk (DIM) are influenced by numerous explanatory factors common to specific farms or individual cows on these farms. Machine learning algorithms offer great flexibility with regard to problems of multicollinearity, missing values, or complex interactions among variables. The objective of this study was to use machine learning algorithms to identify factors affecting the reproductive performance of lactating Holstein cows on large dairy farms. This study used data from farms in the Alta Genetics Advantage progeny-testing program. Production and reproductive records from 153 farms were obtained from on-farm DHI-Plus, Dairy Comp 305, or PCDART herd management software. A survey regarding management, facilities, labor, nutrition, reproduction, genetic selection, climate, and milk production was completed by managers of 103 farms; body condition scores were measured by a single evaluator on 63 farms; and temperature data were obtained from nearby weather stations. The edited data consisted of 31,076 lactation records, 14,804 cows, and 317 explanatory variables for first-service conception rate and 17,587 lactation records, 9,516 cows, and 341 explanatory variables for pregnancy status at 150 DIM. An alternating decision tree algorithm for first-service conception rate classified $75.6 \%$ of records correctly and identified the frequency of hoof trimming maintenance, type of bedding in the dry cow pen, type of cow restraint system, and duration of the voluntary waiting period as key explanatory variables. An alternating decision tree algorithm for pregnancy status at 150 DIM classified $71.4 \%$ of records correctly and identified bunk space per cow, temperature for thawing
\end{abstract}

Received August 8, 2005.

Accepted June 19, 2006.

${ }^{1}$ Corresponding author: kweigel@wisc.edu semen, percentage of cows with low body condition scores, number of cows in the maternity pen, strategy for using a clean-up bull, and milk yield at first service as key factors.

Key words: machine learning, alternating decision tree, fertility, dairy cattle

\section{INTRODUCTION}

Many management practices and environmental factors influence the reproductive performance of a dairy herd, including estrus-detection efficiency, age, nutrition, BCS, semen-handling techniques, transition cow management, calving difficulty, metabolic health, udder health, cow comfort, stocking rate, and heat stress (Lucy, 2001). Evidence exists regarding the impact of some specific factors, such as milk yield (Bagnato and Oltenacu, 1994; Loeffler et al., 1999; Windig et al., 2005), heat stress (Wilson et al., 1998), genetics (Weigel, 2004), energy balance (De Vries and Veerkamp, 2000), udder health (Barker et al., 1998), lameness (Collick et al., 1989; Garbarino et al., 2004), reproductive health (LeBlanc et al., 2002; Sheldon et al., 2002), and hormonal intervention (Pursley et al., 1997). With few exceptions (Windig et al., 2005), these studies have assessed effects of specific management factors independently, and few studies have attempted to evaluate the overall impact of numerous factors affecting reproductive performance simultaneously in a single analysis. Nonetheless, veterinarians, nutritionists, and reproductive consultants must consider all potential explanatory factors jointly to make useful management recommendations on commercial dairy farms.

Numerous measures of reproductive performance have been proposed, including days to first insemination, first-service conception rate, days open, calving interval, services per conception, and 21-d pregnancy rate, among others. Each offers advantages and disadvantages, but a critical factor is the robustness of such variables to differences within and between herds in the duration of the voluntary waiting period (VWP) and use of hormonal products for ovulation synchronization 
(Pursley et al., 1997). Pregnancy status at 150 DIM (i.e., pregnant or nonpregnant) is a composite trait that encompasses estrus-detection efficiency and breeding efficiency and is relatively robust to heterogeneity in the extent of hormonal synchronization and duration of the VWP.

The field of machine learning offers many flexible algorithms that are suitable for analysis of large, complex data sets. Conventional statistical methods, such as regression or ANOVA, require the assumption of a specific parametric function (e.g., linear, quadratic, etc.), and large quantities of data must be discarded if one or more explanatory variables are missing. Machine learning algorithms, on the other hand, can accommodate intricate dependencies among explanatory variables and can function effectively in the presence of missing values for some variables. Therefore, the application of such algorithms for analysis of herd management and performance data or computerized decision making on commercial dairy farms seems very promising (Pietersma et al., 1998).

The objective of this study was to use one type of machine learning algorithm, the alternating decision tree, to identify factors that affect the first-service conception rate or pregnancy status at 150 DIM in highproducing Holstein cows on large dairy farms, using a comprehensive data set with information regarding management, housing, labor, nutrition, genetics, and climate for specific farms and individual cows on these farms.

\section{MATERIALS AND METHODS}

\section{Data}

Information from Holstein cows that calved between January 2000 and August 2004 on 153 large dairy farms that participate in the Alta Genetics (Watertown, WI) Advantage progeny-testing program were used in the present study. These herds were located throughout the United States, with the largest concentrations (in descending order) in Wisconsin, California, New York, Minnesota, Michigan, Washington, Pennsylvania, Iowa, Idaho, Texas, and Ohio. The mean size of these herds was $613 \pm 46$ lactating cows.

Information regarding potential herd-specific and cow-specific explanatory variables was compiled from numerous sources. Test-day milk yields were collected from the DHI milk-recording program and were provided by a dairy records processing center or extracted directly from on-farm DHI-Plus (DHI, Provo, UT), Dairy Comp 305 (Valley Ag Software, Tulare, CA), or PCDART (Dairy Records Management Services, Raleigh, NC) herd management software, as were data regarding insemination dates and pregnancy examina- tion dates and outcomes. Information regarding the maximum daily ambient temperature on the day of insemination was obtained (via the National Climatic Data Center) from weather stations located within 40 $\mathrm{km}$ of these farms, and a single trained evaluator assessed BCS for cows in 63 herds in the Upper Midwest from May to August, 2004. Last, a comprehensive survey was completed by the managers of 103 farms, with the help of Alta Genetics Advantage consultants. This lengthy survey included questions regarding 10 aspects of each dairy operation, including general management issues, sire selection, reproductive management, inseminator training and techniques, heat abatement devices, body condition scoring, facility design and pen movement, nutrition, employee training and management, and cow health and biosecurity. A detailed summary of these data, including means, frequencies, and other descriptive statistics is provided in Caraviello et al. (2006).

The first dependent variable considered in this study was first-service conception rate. In constructing the data set for this variable, only lactation records with at least 1 service were considered. Milk yield was required for a lactation to be included in the analysis, and the test-day milk weight nearest the date of $\mathrm{AI}$ was identified for each lactation record. Lactation records that had no reported outcome (i.e., those that lacked a repeat breeding, a negative pregnancy diagnosis, or a positive pregnancy diagnosis) within $75 \mathrm{~d}$ after the first service were excluded. A minimum of $14 \mathrm{~d}$ was required between consecutive inseminations of the same cow. After editing, the data set for the first-service conception rate contained 31,076 lactation records from 14,804 cows, along with a total of 317 potential explanatory variables.

The second dependent variable considered in this study was pregnancy status at 150 DIM (i.e., pregnant vs. nonpregnant). This variable is a composite indicator of estrus-detection efficiency (i.e., service rate) and breeding efficiency (i.e., conception rate). Because it is not measured until midlactation, this variable is relatively robust to differences between herds in duration of the VWP, as well as to differences between herds in the method and extent of hormonal synchronization before first service, resychronization of later services, or treatment of noncycling cows. In constructing the data set for pregnancy status at 150 DIM, each cow was required to have at least $1 \mathrm{AI}$ in a given lactation, or to have passed 150 DIM without being inseminated. After editing, the data set for pregnancy status at 150 DIM had 17,587 lactation records from 9,516 cows, as well as 341 potential explanatory variables.

Because some categorical explanatory variables did not apply to every farm that responded to the survey, 
a unique value designating "nonapplicable" was assigned to these responses. Other missing or incomplete responses that did not fit into the nonapplicable category were kept as missing values.

\section{Methodology}

After evaluating several machine learning algorithms, including decision trees, Bayesian networks, and instance-based algorithms in a related study, Caraviello (2005) determined that the approach most readily applicable to this study was the alternating decision tree algorithm (Freund and Mason, 1999). Decision trees are hierarchical sets of "if-then" tests (known as nodes) that are used to classify records (or instances) into their most likely outcomes based on various explanatory variables (or attributes). The alternating decision tree is a particular type of tree that relies on a boosting algorithm to improve performance (Freund and Schapire, 1996), and is computationally less demanding than many modern general-purpose machine learning classifiers for large, complex data sets. As compared with other algorithms, the alternating decision tree algorithm tends to build smaller trees that can be more readily interpreted by the end user.

The alternating decision tree algorithm is an iterative procedure in which potential decision nodes corresponding to specific explanatory variables are evaluated at various "cut points" and then added to the decision tree sequentially. Cut points for binary variables may correspond to the presence or absence of a given characteristic (e.g., use of sprinklers for heat abatement), whereas cut points for categorical variables may represent logical combinations of levels (e.g., purchased cows from a cattle dealer, auction barn, or via private sale), and cut points for continuous variables may represent key thresholds (e.g., durations of VWP $<60$ vs. $\geq 60 \mathrm{~d}$ ). At each iteration, the cut point for a given variable is chosen such that the number of correctly classified records in the training set is maximized while the number of incorrectly classified records in the training set is minimized. Furthermore, "heavy branches" of the tree (i.e., branches or paths that are reached by a large number of records) are expanded preferentially, and this ensures that effort is not wasted in attempting to discriminate among a few unique, outlier records.

Each individual record flows through the decision tree to determine its classification, and decision nodes within the tree determine the various paths (i.e., branches) to be followed. When the record reaches a particular decision node, it follows the path of the "child" corresponding to the outcome of the "if-then" decision rule. A given node may or may not be reached by every record (i.e., if a particular variable is missing or not applicable, or if a condition present at an ancestral node is not satisfied). Therefore, there is no need to discard records with one or more missing explanatory variables, and this can avoid a tremendous loss of data. Nodes are numbered, indicating the order in which explanatory variables were added to the tree (the first variables added tend to be those that provide the highest proportion of correctly classified records). Nodes at the first level of the tree are independent, but the significance of nodes at the second and deeper levels depends on decisions obtained at "ancestral" nodes at higher levels within the tree. In this manner, decision trees can account for complex dependencies and interactions among explanatory variables.

The alternating decision tree algorithm also associates a prediction value with each node, and this allows each node to be interpreted independently from other nodes. More important, the value associated with each prediction node encountered along the path taken by a given record is added to that record's final summation, and the final summation subsequently determines the classification status of the record (pregnant vs. nonpregnant in this case). If the assumed threshold is zero, as is normally the case for a binary outcome such as pregnancy status, the classification of a record will be positive (i.e., pregnant) if the final sum is greater than zero and will be negative (i.e., nonpregnant) if the final sum is less than zero. Each record follows multiple paths as it goes through the tree, so the lack of 1 explanatory variable does not prevent classification, because only the values of nodes that can be reached will contribute to the final sum. Furthermore, because each node provides only a small contribution, it is unlikely that a missing value will have a major impact on the final sum, especially if it corresponds to a node that has few descendents or a node that is far from the root of the tree.

The absolute value of the final sum determines the classification margin, a measure of confidence associated with the classification of a given record. The confidence level for a positively classified record increases as the overall sum increases (i.e., as the sum becomes more positive), and the confidence level for a negatively classified record increases as the overall sum decreases (i.e., as the sum becomes more negative). In some applications, the classification margin is as important as the classification itself. The receiver operating characteristic curve allows one to choose the most appropriate threshold (not necessarily zero) for a specific application, and the area under this curve can be used, along with cross-validation results, as a measure of the overall predictive ability of the algorithm.

The Weka package (Witten and Frank, 2000), implemented in Java, was used to develop the alternating 
decision trees discussed herein. This package provides a flexible framework for comparing algorithms and trees through cross-validation. In the present study, 10-fold cross-validation was used. In each of a series of 10 analyses, $90 \%$ of the data constituted the "training set," which was used to build the decision tree, and the remaining 10\% constituted the "testing set" (also known as the "prediction set"), which was used to evaluate the predictive ability of the resulting tree.

To aid interpretation of the decision trees developed herein, the records of 2 example cows were classified using the decision tree for first-service conception rate. Furthermore, the predicted probability of pregnancy by 150 DIM was computed by using logistic regression for each continuous variable (LOGIST procedure; SAS Inst. Inc., Cary, NC) or a generalized linear model for each discrete variable (CATMOD procedure; SAS Inst., Inc.) that was included in the corresponding decision tree. The purpose of the logistic regression analysis was to aid interpretation of the effects of variables chosen by the decision tree. Many of these analyses corresponded to decision nodes that were nested within (i.e., were children of) prediction nodes located at higher levels of the tree, and the probabilities were computed using only those records that reached the corresponding decision node (i.e., records for which variables at ancestor nodes satisfied the conditions of the corresponding cut points).

\section{RESULTS AND DISCUSSION}

\section{First-Service Conception Rate}

Figure 1 shows the alternating decision tree for firstservice conception rate. Oval structures represent the decision nodes, including a number that indicates the iteration at which that node was added to the tree, as well as the code assigned to that explanatory variable. Cut points are interpreted differently for continuous explanatory variables (values can be less than or greater than the cut point) vs. discrete explanatory variables (values must be equal or unequal to one of the categories), and these are shown along the connectors of the decision and prediction nodes. Prediction nodes are represented as rectangular structures in the tree, and these have prediction values (arbitrarily designated as "a" and "b") associated with them. Table 1 contains a detailed description of the meaning of each node, together with its cut point and its prediction values. Explanatory variables in Table 1 are ordered in the sequence in which they were added to the decision tree in Figure 1.

The decision tree in Figure 1 contains 22 nodes. It was induced using the entire data set and the same algorithm that correctly classified (predicted the out- come of) $75.6 \%$ of first-insemination records using 10 fold cross-validation. Among the $24.4 \%$ of records that were classified incorrectly, $0.7 \%$ represented false positives and $99.3 \%$ represented false negatives. The area under the receiver operating characteristic curve (not shown), a graphical representation of the percentage of false positives (on the $x$-axis) and true positives (on the $y$-axis), was 0.68 , and when true-positive detection rates were set to 0.5 and 1 , the false-positive detection rates were 0.3 and 0.8 , respectively (algorithms with poor predictive ability would have false-positive detection rates close to 0.5 and 1 , respectively). The overall mean first-service conception rate was $25.2 \%$ in this data set. The root node of the decision tree, which was computed as $1 / 2 \ln [0.252 /(1-0.252)]$, was -0.545 , indicating a greater chance for failure than conception at first service.

As shown in Table 1, a total of 4,048 insemination records were from cows residing in herds for which maintenance hoof trimming occurred less than once annually (i.e., response category 1 ). At decision node 1 , prediction node "a" assigns a value of -0.597 to records pertaining to category 1 (hoof trimming less than once annually), indicating a reduced probability of conception at first service. The path below prediction node "b" for this variable is followed by all other records that do not have missing values for frequency of maintenance hoof trimming. Lameness is a common problem on freestall operations in North America (Cook, 2003), and it has been shown to delay the onset of ovarian activity (Garbarino et al., 2004) and depress the conception rate (Collick et al., 1989). Regular hoof trimming has been shown to be a critical component of lameness prevention in dairy herds (Manske et al., 2002).

Several farms move their cows out of the close-up dry cow pen, which had mean entry and exit times of $20 \mathrm{~d}$ prepartum and $3 \mathrm{~d}$ prepartum, respectively, later than $1.5 \mathrm{~d}$ before calving, as shown by decision node 2 in Table 1. Cows on these farms had a lesser probability of conception at first service, as indicated by a value of -0.602 at prediction node "b." A possible explanation is the relationship between housing or bedding and exposure to pathogens near parturition. Several studies have emphasized the importance of proper management of peripartum cows, particularly with regard to avoiding postpartum endometritis (Loeffler et al., 1999; LeBlanc et al., 2002; Sheldon et al., 2002). In a very large study, LeBlanc et al. (2002) showed that cows having postpartum endometritis had a lesser mean conception rate at first service $(29.8 \%)$ than healthy cows (37.9\%). The corresponding relative risk of pregnancy in infected vs. healthy cows (risk of 1.00), after correcting for environmental factors, was 0.69. In addition, Sheldon et al. (2002) reported a decline from 35 to $5 \%$ 


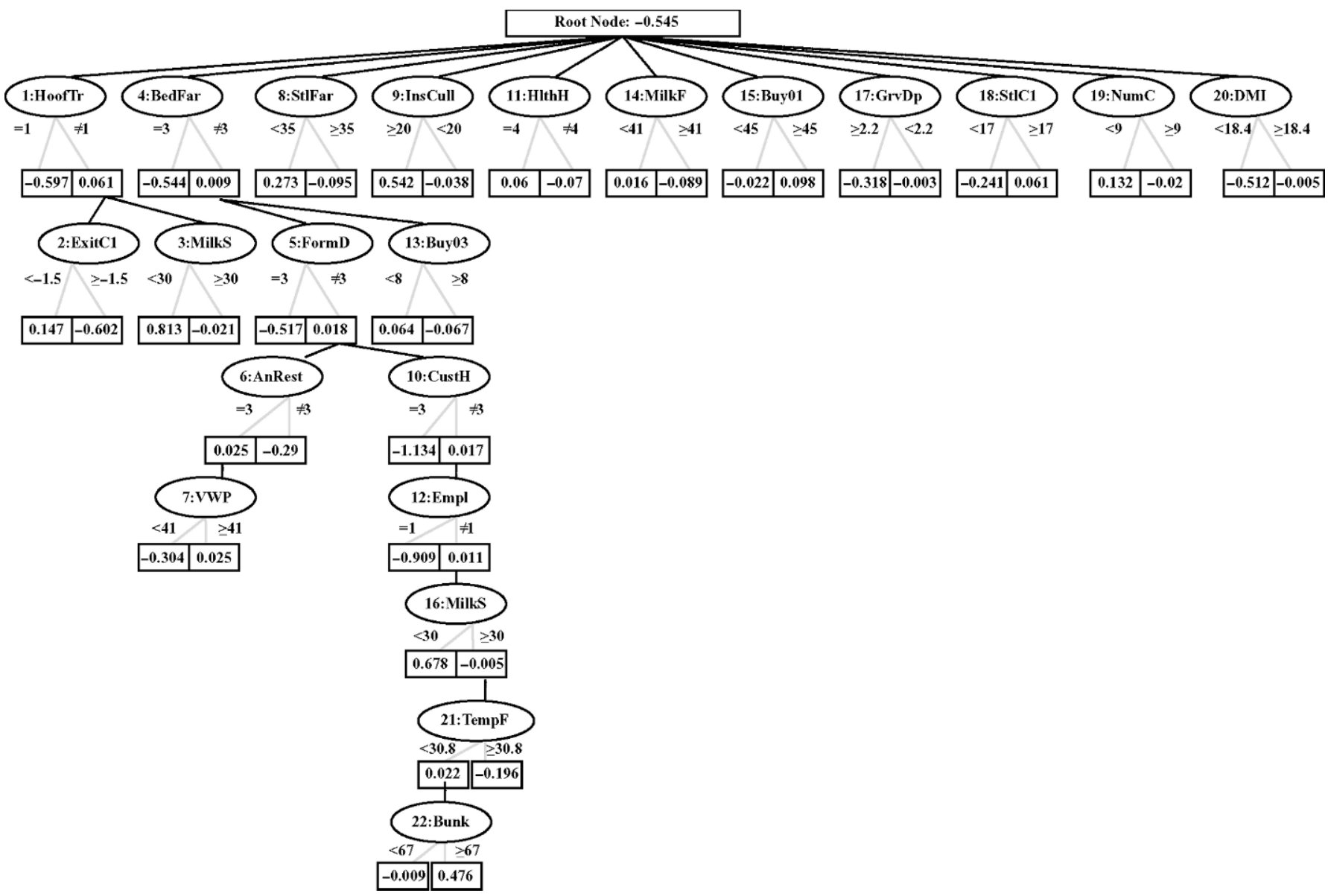

Figure 1. Alternating decision tree classifier for explaining conception at first service. Decision nodes are represented by an oval structure, and each contains a number (in bold font) that indicates the iteration at which that node was added to the tree, followed by the code assigned to that variable. Cut points are shown along the connectors between decision nodes and the prediction nodes ("a" and "b"), in which the latter are represented by rectangular structures and contain the corresponding prediction values.

in dominant follicle selection on the ipsilateral ovary, with respect to the previously gravid uterine horn, in cows with elevated early postpartum uterine bacterial counts. Bacterial contamination also was shown to inhibit the growth and function of the dominant follicle, leading to a smaller, slower-developing dominant follicle and a corresponding reduction in the production of estradiol. Loeffler et al. (1999) emphasized the importance of maintaining high peripartum feed intake, as well as the importance of avoiding displaced abomasum, cystic ovaries, metritis, mastitis, or lameness within $30 \mathrm{~d}$ of an insemination.

Decision node 3 , which is based on the weight of milk shipped per cow per day, had a very low cut point (shown in Table 1), because only 457 records corresponded to cows on farms that shipped less than $30 \mathrm{~kg} /$ cow per $d$. Therefore, very few records were affected by the prediction node "a" value of 0.813 . Decision nodes 9 (number of inseminations until a culling decision is made), 10 (proportion of heifers sent to a custom grower), 12 (difficulty in keeping good farm employees), 16 ( $\mathrm{kg}$ of milk shipped/cow per d), 20 (DMI for nonpregnant cows), and 22 (bunk space/cow in the breeding pens) each had relatively extreme cut points as well, such that only $505,245,488,273,569$, and 352 records, respectively, reached one of the corresponding prediction nodes. Therefore, despite being important contributors to the predictive ability of this tree, these nodes provide little insight into possible relationships between the corresponding explanatory variables and reproductive performance, and one should not attempt to draw conclusions based on data from 1 or 2 specific farms. This illustrates a common challenge with the interpretation of decision trees. The presence of nodes that are reached by few highly influential records tends to hamper user interpretation. Preferential expansion of heavy branches in the tree tends to limit the generation of these nodes with extreme cut points to the cases 
Table 1. Variables included in the alternating decision tree for conception at first service in Figure 1, ordered by the sequence in which they were added to the tree, along with corresponding cut points and prediction values ${ }^{1}$

\begin{tabular}{|c|c|c|c|c|}
\hline Node: code & Question & Possible responses & $\begin{array}{l}\text { Cut point (a) } \\
\text { Prediction (a) }\end{array}$ & $\begin{array}{l}\text { Cut point (b) } \\
\text { Prediction (b) }\end{array}$ \\
\hline 1: HoofTr & $\begin{array}{l}\text { How frequently does maintenance hoof } \\
\text { trimming take place in your herd? }\end{array}$ & $\begin{array}{l}1 \text { Less than once annually }\left(\mathrm{N}_{\mathrm{h}}=17\right) \\
2 \text { Once annually }\left(\mathrm{N}_{\mathrm{h}}=15\right) \\
3 \text { Twice annually }\left(\mathrm{N}_{\mathrm{h}}=27\right) \\
4 \text { More than } 3 \text { times annually }\left(\mathrm{N}_{\mathrm{h}}=43\right)\end{array}$ & $\begin{array}{l}\text { Category }=1 \\
-0.597 \\
\left(\mathrm{~N}_{\mathrm{a}}=4,048\right)\end{array}$ & $\begin{array}{l}\text { Category } \neq 1 \\
0.061 \\
\left(\mathrm{~N}_{\mathrm{a}}=27,028\right)\end{array}$ \\
\hline 2: ExitCl & $\begin{array}{l}\text { When do cows exit from the } \\
\text { close-up dry cow pen? }\end{array}$ & Continuous (no. days relative to calving) & $\begin{array}{l}\text { Before }-1.5 \mathrm{~d} \\
0.147 \\
\left(\mathrm{~N}_{\mathrm{a}}=6,741\right)\end{array}$ & $\begin{array}{l}\text { After }-1.5 \mathrm{~d} \\
-0.602 \\
\left(\mathrm{~N}_{\mathrm{a}}=1,479\right)\end{array}$ \\
\hline 4: BedFar & $\begin{array}{l}\text { What type of bedding is used } \\
\text { for the far-off dry cows? }\end{array}$ & $\begin{array}{l}1 \text { Sand }\left(\mathrm{N}_{\mathrm{h}}=30\right) \\
2 \text { Mattress }\left(\mathrm{N}_{\mathrm{h}}=14\right) \\
3 \text { Sawdust }\left(\mathrm{N}_{\mathrm{h}}=13\right) \\
4 \text { Other }\left(\mathrm{N}_{\mathrm{h}}=19\right)\end{array}$ & $\begin{array}{l}\text { Category }=3 \\
-0.544 \\
\left(\mathrm{~N}_{\mathrm{a}}=1,783\right)\end{array}$ & $\begin{array}{l}\text { Category } \neq 3 \\
0.009 \\
\left(\mathrm{~N}_{\mathrm{a}}=29,293\right)\end{array}$ \\
\hline 6: AnRest & $\begin{array}{l}\text { When cows are bred, what type } \\
\text { of restraint system is used? }\end{array}$ & $\begin{array}{l}1 \text { Self-locking manger stall }\left(\mathrm{N}_{\mathrm{h}}=68\right) \\
2 \text { Palpation rail }\left(\mathrm{N}_{\mathrm{h}}=21\right) \\
3 \text { Cow-handling chute }\left(\mathrm{N}_{\mathrm{h}}=11\right) \\
4 \text { Cows bred in milking parlor }\left(\mathrm{N}_{\mathrm{h}}=3\right) \\
5 \text { Cows bred in parlor return lane }\left(\mathrm{N}_{\mathrm{h}}=6\right) \\
6 \text { Corner cows in pen or free stall }\left(\mathrm{N}_{\mathrm{h}}=24\right) \\
7 \text { Stanchion or tie stall }\left(\mathrm{N}_{\mathrm{h}}=6\right)\end{array}$ & $\begin{array}{l}\text { Category }=3 \\
-0.29 \\
\left(\mathrm{~N}_{\mathrm{a}}=2,690\right)\end{array}$ & $\begin{array}{l}\text { Category } \neq 3 \\
0.025 \\
\left(\mathrm{~N}_{\mathrm{a}}=25,327\right)\end{array}$ \\
\hline 7: VWP & $\begin{array}{l}\text { What is the voluntary waiting period } \\
\text { for second- and later-lactation cows? }\end{array}$ & Continuous (no. days postpartum) & $\begin{array}{l}<41 \mathrm{~d} \\
-0.304 \\
\left(\mathrm{~N}_{\mathrm{a}}=2314\right)\end{array}$ & $\begin{array}{l}\geq 41 \mathrm{~d} \\
0.025 \\
\left(\mathrm{~N}_{\mathrm{a}}=23,013\right)\end{array}$ \\
\hline 8: StlFar & $\begin{array}{l}\text { How many stalls do you have in the } \\
\text { far-off dry cow pen? }\end{array}$ & Continuous (no. cows) & $\begin{array}{l}<35 \text { stalls } \\
0.273 \\
\left(\mathrm{~N}_{\mathrm{a}}=1,926\right)\end{array}$ & $\begin{array}{l}\geq 35 \text { stalls } \\
-0.095 \\
\left(\mathrm{~N}_{\mathrm{a}}=7,867\right)\end{array}$ \\
\hline 12: Empl & $\begin{array}{l}\text { In terms of employee management } \\
\text { on your operation, how difficult is it } \\
\text { to keep good farm employees? }\end{array}$ & $\begin{array}{l}1 \text { (very difficult) }\left(\mathrm{N}_{\mathrm{h}}=2\right) \\
2\left(\mathrm{~N}_{\mathrm{h}}=12\right) \\
3\left(\mathrm{~N}_{\mathrm{h}}=23\right) \\
4\left(\mathrm{~N}_{\mathrm{h}}=45\right) \\
5 \text { (very easy) }\left(\mathrm{N}_{\mathrm{h}}=15\right)\end{array}$ & $\begin{array}{l}\text { Category = } 1 \\
-0.909 \\
\left(\mathrm{~N}_{\mathrm{a}}=488\right)\end{array}$ & $\begin{array}{l}\text { Category } \neq 1 \\
0.011 \\
\left(\mathrm{~N}_{\mathrm{a}}=27,284\right)\end{array}$ \\
\hline 13: Buy03 & $\begin{array}{l}\text { Approximately how many cows did you } \\
\text { purchase in } 2003 ?\end{array}$ & Continuous (no. cows) & $\begin{array}{l}<8 \text { cows } \\
0.064 \\
\left(\mathrm{~N}_{\mathrm{a}}=14,600\right)\end{array}$ & $\begin{array}{l}\geq 8 \text { cows } \\
-0.067 \\
\left(\mathrm{~N}_{\mathrm{a}}=14,693\right)\end{array}$ \\
\hline 14: MilkF & $\begin{array}{l}\text { Milk yield at first service of the specific } \\
\text { cow that was inseminated }\end{array}$ & Continuous (kg/d) & $\begin{array}{l}<41 \mathrm{~kg} / \mathrm{d} \\
0.016 \\
\left(\mathrm{~N}_{\mathrm{a}}=13,721\right)\end{array}$ & $\begin{array}{l}\geq 41 \mathrm{~kg} / \mathrm{d} \\
-0.089 \\
\left(\mathrm{~N}_{\mathrm{a}}=13,238\right)\end{array}$ \\
\hline 15: Buy01 & $\begin{array}{l}\text { Approximately how many cows did you } \\
\text { purchase in } 2001 ?\end{array}$ & Continuous (no. cows) & $\begin{array}{l}<45 \text { cows } \\
-0.022 \\
\left(\mathrm{~N}_{\mathrm{a}}=18,315\right)\end{array}$ & $\begin{array}{l}\geq 45 \text { cows } \\
0.098 \\
\left(\mathrm{~N}_{\mathrm{a}}=12,761\right)\end{array}$ \\
\hline 16: MilkS & $\begin{array}{l}\text { Throughout the year, how much milk do you } \\
\text { normally ship per cow per day? }\end{array}$ & Continuous (kg/cow per d) & $\begin{array}{l}<30 \mathrm{~kg} / \mathrm{d} \\
0.678 \\
\left(\mathrm{~N}_{\mathrm{a}}=273\right)\end{array}$ & $\begin{array}{l}\geq 30 \mathrm{~kg} / \mathrm{d} \\
-0.005 \\
\left(\mathrm{~N}_{\mathrm{a}}=25,999\right)\end{array}$ \\
\hline
\end{tabular}


Table 1 (Continued). Variables included in the alternating decision tree for conception at first service in Figure 1, ordered by the sequence in which they were added to the tree, along with corresponding cut points and prediction values ${ }^{1}$

\begin{tabular}{|c|c|c|c|c|}
\hline Node: code & Question & Possible responses & $\begin{array}{l}\text { Cut point (a) } \\
\text { Prediction (a) }\end{array}$ & $\begin{array}{l}\text { Cut point (b) } \\
\text { Prediction (b) }\end{array}$ \\
\hline 17: GrvDp & $\begin{array}{l}\text { What is the depth of the grooves in your } \\
\text { concrete (if it has grooves) } \\
\text { at the breeding pen? }\end{array}$ & Continuous (depth in $\mathrm{cm}$ ) & $\begin{array}{l}<2.2 \mathrm{~cm} \\
-0.003 \\
\left(\mathrm{~N}_{\mathrm{a}}=24,990\right)\end{array}$ & $\begin{array}{l}\geq 2.2 \mathrm{~cm} \\
-0.318 \\
\left(\mathrm{~N}_{\mathrm{a}}=1,570\right)\end{array}$ \\
\hline 18: StlCl & $\begin{array}{l}\text { What is the number of the stalls in the } \\
\text { close-up dry cow pen? }\end{array}$ & Continuous (no. cows) & $\begin{array}{l}<17 \text { stalls } \\
-0.241 \\
\left(\mathrm{~N}_{\mathrm{a}}=1,034\right)\end{array}$ & $\begin{array}{l}\geq 17 \text { stalls } \\
0.061 \\
\left(\mathrm{~N}_{\mathrm{a}}=8,112\right)\end{array}$ \\
\hline 20: DMI & $\begin{array}{l}\text { What is the typical DM intake for the } \\
\text { nonpregnant cow groups? }\end{array}$ & Continuous (kg/d) & $\begin{array}{l}<18.4 \mathrm{~kg} / \mathrm{d} \\
-0.512 \\
\left(\mathrm{~N}_{\mathrm{a}}=569\right)\end{array}$ & $\begin{array}{l}\geq 18.4 \mathrm{~kg} / \mathrm{d} \\
-0.005 \\
\left(\mathrm{~N}_{\mathrm{a}}=26,316\right)\end{array}$ \\
\hline 21: TempF & $\begin{array}{l}\text { Outside temperature on the specific day } \\
\text { of first service on which the cow } \\
\text { was inseminated }\end{array}$ & Continuous $\left({ }^{\circ} \mathrm{C}\right)$ & $\begin{array}{l}<30.8^{\circ} \mathrm{C} \\
0.022 \\
\left(\mathrm{~N}_{\mathrm{a}}=24,589\right)\end{array}$ & $\begin{array}{l}\geq 30.8^{\circ} \mathrm{C} \\
-0.196 \\
\left(\mathrm{~N}_{\mathrm{a}}=1,410\right)\end{array}$ \\
\hline
\end{tabular}

${ }^{1}$ For discrete variables, $\mathrm{N}_{\mathrm{h}}$ indicates the number of herds in that category. For all variables, $\mathrm{N}_{\mathrm{a}}$ indicates the number of individual cows reaching that prediction node.

in which very significant gains in predictive ability are obtained.

Decision node 4 corresponds to the type of bedding material in the far-off dry cow pen, which had mean entry and exit times of 53 and $21 \mathrm{~d}$ prepartum, respectively. As shown in Table 1, a total of 1,783 cows were located on farms that used sawdust, and as indicated by the value of -0.544 at prediction node "a," these cows had a much smaller probability of conception at first service than cows housed on sand or mattresses. This result most likely reflects a tendency for a greater incidence of disorders such as metritis or mastitis on farms that use organic bedding, because such infections subsequently impair reproductive performance (Barker et al., 1998). A large proportion of clinical mastitis cases become apparent during the first $2 \mathrm{wk}$ of lactation (Goff and Horst, 1997), and the rate of infection during this period is heavily influenced by dry cow management practices. Zdanowicz et al. (2004) reported that sawdust bedding contains more bacteria than sand bedding, and that cows housed on sawdust had twice as many coliform bacteria and 6 times as many Klebsiella bacteria on the teat ends as cows housed on sand.

As indicated by decision node 5 , herds in which a veterinarian was responsible for formulating the ration had poorer first-service conception rates, with a prediction node "a" value of -0.517 . This prediction node was reached by only 1,276 cows on 5 farms, however, and one should not draw conclusions about the ability of veterinarians to formulate diets based on such limited data. Decision node 6 indicates a smaller probability of conception, as noted by a prediction node "a" value of -0.29 , among cows that were bred in cow-handling chutes, compared with those inseminated using other types of restraints, although the explanation for this relationship is not obvious. Decision node 7 indicates that herds with a VWP of $<41 \mathrm{~d}$ had a smaller probability of conception (prediction node "a" value of -0.304) than herds with a longer VWP. Note that node 5 was reached only by records from herds that do not use sawdust bedding in the far-off dry cow pen, and that nodes 6 and 7 were reached only by the subset of these herds in which diets were formulated by someone other than a veterinarian.

Decision node 8 indicates that herds with fewer than 35 stalls in the far-off dry cow pen have greater conception rates (prediction node "a" value of 0.273 ). Decision node 11 , which is based on the producer's degree of satisfaction with the health of replacement heifers, illustrates the challenge of proper and informative coding of response categories. Prediction node "a," with a corresponding value of 0.06 , indicates a slight advantage in conception rate on farms that are reasonably satisfied (score of 4 on a 5-point scale) with the health of their heifers. It is not obvious why the 45 herds that were extremely satisfied (score of 5) did not realize a similar gain in first-service conception rate. In practice, it may be more useful to treat ordinal variables, such as these, in a continuous rather than a categorical manner.

Decision node 13 , with a prediction node "a" value of 0.064 , seems to indicate that farms that purchased few $(<8)$ or no replacements in 2003 had a greater probabil- 
ity of conception. This could be taken as an indicator that biosecurity and reproductive performance are related, but such a conclusion seems contradictory to the outcome of decision node 15 , which assigns a prediction node "b" value of 0.098 to herds that purchased $\geq 45$ replacements in 2001. Numerous authors have speculated about the impact of biosecurity, herd expansion, and herd size on reproductive performance (Bagnato and Oltenacu, 1994; Stahl et al., 1999; Lucy, 2001). Stahl et al. (1999) noted that an increase in the number of cows is not typically followed by a proportional increase in the number of employees. Pursley et al. (1997) noted an increased interest in hormonal synchronization and timed AI programs among larger herds.

The prediction node "a" value at decision node 14 indicates a greater probability of conception at first service among cows that had daily milk yields of $<41$ $\mathrm{kg}$ on the test date closest to insemination. The impact of milk production on fertility has been discussed in numerous studies (Loeffler et al., 1999; Westwood et al., 2002; Windig et al., 2005). In an association study, Washburn et al. (2002) examined the historical relationship between milk yield and conception rate, noting that average $4 \% \mathrm{FCM}$ yield increased from $6,400 \mathrm{~kg} /$ cow per yr to $7,800 \mathrm{~kg} / \mathrm{cow}$ per yr from the mid-1970s to the mid-1990s, whereas the average conception rate declined from 55 to $35 \%$ during the same period. Others (Bagnato and Oltenacu, 1994; Loeffler et al., 1999; Windig et al., 2005) reported that the number of inseminations and the conception rate at first service were antagonistically correlated with milk production. Gröhn and Rajala-Schultz (2000) reported an odds ratio of 0.92 for conception in cows producing $>2,541 \mathrm{~kg}$ cumulative milk yield during the first $60 \mathrm{DIM}$, compared with cows with a lesser cumulative yield.

Decision nodes 17 (depth of concrete grooves in the breeding pen), 18 (number of stalls in the close-up dry cow pen), and 19 (number of cows in the close-up dry cow pen) appear in the first level of the tree (i.e., they are not nested within any ancestral nodes) and are related to facilities and housing. Results seem to indicate a greater probability of conception in herds with flooring grooves $<2.2 \mathrm{~cm}$ deep in the breeding pen, and herds with $\geq 17$ stalls or $<9$ cows in the close-up dry cow pen.

Last, decision node 21 was based on the maximum temperature at the nearest weather station on the day of AI. The prediction node "a" value of 0.022 indicates greater probability of conception at temperatures $<30.8^{\circ}$ C. Several authors (Wilson et al., 1998; Ravagnolo and Misztal, 2002) have addressed the impact of heat stress on reproductive performance, and have noted that the temperature-humidity index (THI) on the day of AI had the largest effect on the 45-d nonre- turn rate, followed by the THI $2 \mathrm{~d}$ before, $5 \mathrm{~d}$ before, and $5 \mathrm{~d}$ after AI. Ravagnolo and Misztal (2002) also confirmed a steep reduction in the 45-d nonreturn rate (about $0.5 \%$ per unit increase in THI) for THI values $>68$ and noted that primiparous cows were slightly more susceptible to increases in the THI than multiparous cows. Although the THI is readily available from weather stations, these may be not accurately reflect heat stress on individual farms, because the use of fans and sprinklers can greatly reduce the correlation between THI within the barn and THI at the nearest weather station.

Table 2 illustrates the methodology for predicting the outcome of first service for 2 example cows using the alternating decision tree in Figure 1. As noted earlier, the root node is negative $(-0.545)$, because the average first-service conception rate was $25.2 \%$. Both cows receive a contribution of 0.061 to the final sum from node 1 , because neither comes from a herd that practices maintenance hoof trimming less than once annually. Based on differences in the time at which cows exit from the close-up dry cow pen on the corresponding farms, cow A gets a contribution of 0.147 from node 2, whereas cow B gets a contribution of -0.602 . Both cows come from farms that ship $\geq 30 \mathrm{~kg}$ of milk/cow per $\mathrm{d}$, so both receive a prediction value of -0.021 from node 3 . Likewise, neither farm uses sawdust to bed the far-off dry cow pen or a veterinarian to formulate the diet, so both receive contributions of 0.009 and 0.018 from nodes 4 and 5, respectively. Because cow 1 comes from a farm that uses a cow-handling chute, she receives a prediction value of -0.29 from node 6 , but she does not reach decision node 7 , because she does not satisfy the necessary condition (category $=3$ ) at the ancestral prediction node 6 . Cow 2 , on the other hand, gets contributions to the final sum of 0.025 from nodes 6 and 7 . This process continues as each record passes through every branch and every node in the decision tree, with the exception of nodes that cannot be reached (e.g., nodes 12, 16, 21, and 22 for cow 2) and nodes corresponding to missing data points (e.g., node 18 for cow 1 ). Next, the prediction values are summed across nodes for each cow. Because a threshold of zero was used, the final sums of 0.131 and -2.251 lead to classifications (i.e., predicted outcomes) of "pregnant" for cow 1 and "nonpregnant" for cow 2. Note that the absolute value of the final sum is much greater for cow 2 (2.251) than for cow 1 (0.131), indicating a larger classification margin for cow 2 and a greater degree of confidence in her predicted nonpregnant outcome (compared with the predicted pregnant outcome for cow 1 ).

\section{Pregnancy Status at 150 DIM}

The alternating decision tree for predicting pregnancy status at 150 DIM is shown in Figure 2. Descrip- 
Table 2. Predicted outcome of conception at first service, based on the alternating decision tree in Figure 1 and corresponding solutions in Table 1 , for 2 example cows

\begin{tabular}{|c|c|c|c|c|}
\hline \multirow[b]{2}{*}{ Node: code } & \multicolumn{2}{|c|}{ Cow 1} & \multicolumn{2}{|c|}{ Cow 2} \\
\hline & Response & Prediction & Response & Prediction \\
\hline Root & - & -0.545 & - & -0.545 \\
\hline 1: HoofTr & Twice annually & +0.061 & Once annually & +0.061 \\
\hline 2: ExitCl & $-3.5 \mathrm{~d}$ & +0.147 & $-1.0 \mathrm{~d}$ & -0.602 \\
\hline 3: MilkS & $45 \mathrm{~kg}$ & -0.021 & $33 \mathrm{~kg}$ & -0.021 \\
\hline 4: BedFar & Sand & +0.009 & Mattress & +0.009 \\
\hline 5: FormD & Consultant & +0.018 & Farm employee & +0.018 \\
\hline 6: AnRest & Handling chute & -0.290 & Self-lock & +0.025 \\
\hline 7: VWP & (node not reached) & - & $50 \mathrm{~d}$ & +0.025 \\
\hline 8: StlFar & 30 stalls & +0.273 & 50 stalls & -0.095 \\
\hline 9: InsCull & 8 services & -0.038 & 12 services & -0.038 \\
\hline 10: CustH & None & +0.017 & Most & -1.134 \\
\hline 11: HlthH & Score $=3$ & -0.070 & Score $=4$ & +0.060 \\
\hline 12: Empl & Score $=5$ & +0.011 & (node not reached) & - \\
\hline 13: Buy03 & 100 cows & -0.067 & 0 cows & +0.064 \\
\hline 14: MilkF & $60 \mathrm{~kg}$ & -0.089 & $45 \mathrm{~kg}$ & -0.089 \\
\hline 15: Buy01 & 200 cows & +0.098 & 30 cows & -0.022 \\
\hline 16: MilkS & $45 \mathrm{~kg}$ & -0.005 & (node not reached) & - \\
\hline 17: GrvDp & $2 \mathrm{~cm}$ & -0.003 & $2 \mathrm{~cm}$ & -0.003 \\
\hline 18: StlCl & (not reported) & - & 30 stalls & +0.061 \\
\hline 19: NumC & 5 cows & +0.132 & 20 cows & -0.020 \\
\hline 20: DMI & $35 \mathrm{~kg}$ & -0.005 & $25 \mathrm{~kg}$ & -0.005 \\
\hline 21: TempF & $25^{\circ} \mathrm{C}$ & +0.022 & (node not reached) & - \\
\hline 22: Bunk & $70 \mathrm{~cm}$ & +0.476 & (node not reached) & - \\
\hline Final sum & & +0.131 & \multirow{2}{*}{\multicolumn{2}{|c|}{ Not pregnant ${ }^{-2.251}$}} \\
\hline Classification & \multicolumn{2}{|c|}{ Pregnant } & & \\
\hline
\end{tabular}

tions of the codes assigned to specific variables in Figure 2 are given in Table 3, along with the corresponding cut points and prediction values. The decision tree contained 25 nodes, and was induced using the entire data set and the same algorithm that correctly classified the pregnancy status of $71.4 \%$ of cows using 10 -fold crossvalidation. Among the $28.6 \%$ of records that were classified incorrectly, $83.7 \%$ represented false positives and $16.3 \%$ represented false negatives. The area under the receiver operating characteristic curve (not shown) was 0.73 , and when true-positive detection rates were set to 0.5 and 1 , the false-positive detection rates were 0.2 and 0.6 , respectively. The aforementioned area under the receiver operating characteristic curve and the corresponding false-positive rates indicate that the alternating decision tree algorithm had greater predictive ability for pregnancy status at 150 DIM than for firstservice conception rate. Overall, $60.7 \%$ of the records corresponded to lactations in which the cow became pregnant by 150 DIM. Therefore, as shown in Figure 2 , the root node has a positive prediction value of 0.218 . The value of the root node for status at 150 DIM (0.218) was much smaller than the corresponding value for first-service conception rate $(-0.545)$, and this likely contributed to greater predictive ability of the decision tree for this variable.

Node 1 corresponds to the amount of bunk space per cow in the breeding pens. The cut point was $36 \mathrm{~cm}$ per cow, and the value of -0.875 for prediction node "a" indicates a much greater percentage of nonpregnant cows at 150 DIM in herds with $<36 \mathrm{~cm}$ of bunk space per cow. It is important to note that only 6 herds reported bunk space $<36 \mathrm{~cm}$ per cow. Pens with 3 rows of stalls typically have less bunk space per cow than pens with only 2 rows of stalls when both are filled to a $100 \%$ stocking density. Average bunk space $<36 \mathrm{~cm}$ per cow would typically be associated with overstocked 3 -row pens. As shown in Figure 3, the predicted probability of pregnancy by 150 DIM appeared to increase linearly as bunk space per cow increased from roughly 30 to $60 \mathrm{~cm}$. Other recent studies have emphasized the importance of adequate bunk space. Calamari et al. (2003) noted that inadequate bunk space can affect eating behavior, milk production, and metabolic health, particularly among primiparous cows. In addition, Grant and Albright (2001) identified bunk space as a key factor in determining optimal group size on large dairy farms. In a recent study that focused specifically on the impact of feed intake on fertility, Westwood et al. (2002) observed that cows that consumed $>4.03 \%$ of BW during the first 110 DIM had nearly 2 times greater risk of being pregnant by 150 DIM than those that consumed $<3.45 \%$ of BW during the same period.

Node 2, which was a child of prediction node "b" at node 1 (i.e., it was reached by only those herds that provided $\geq 36 \mathrm{~cm}$ of bunk space per cow), corresponded 


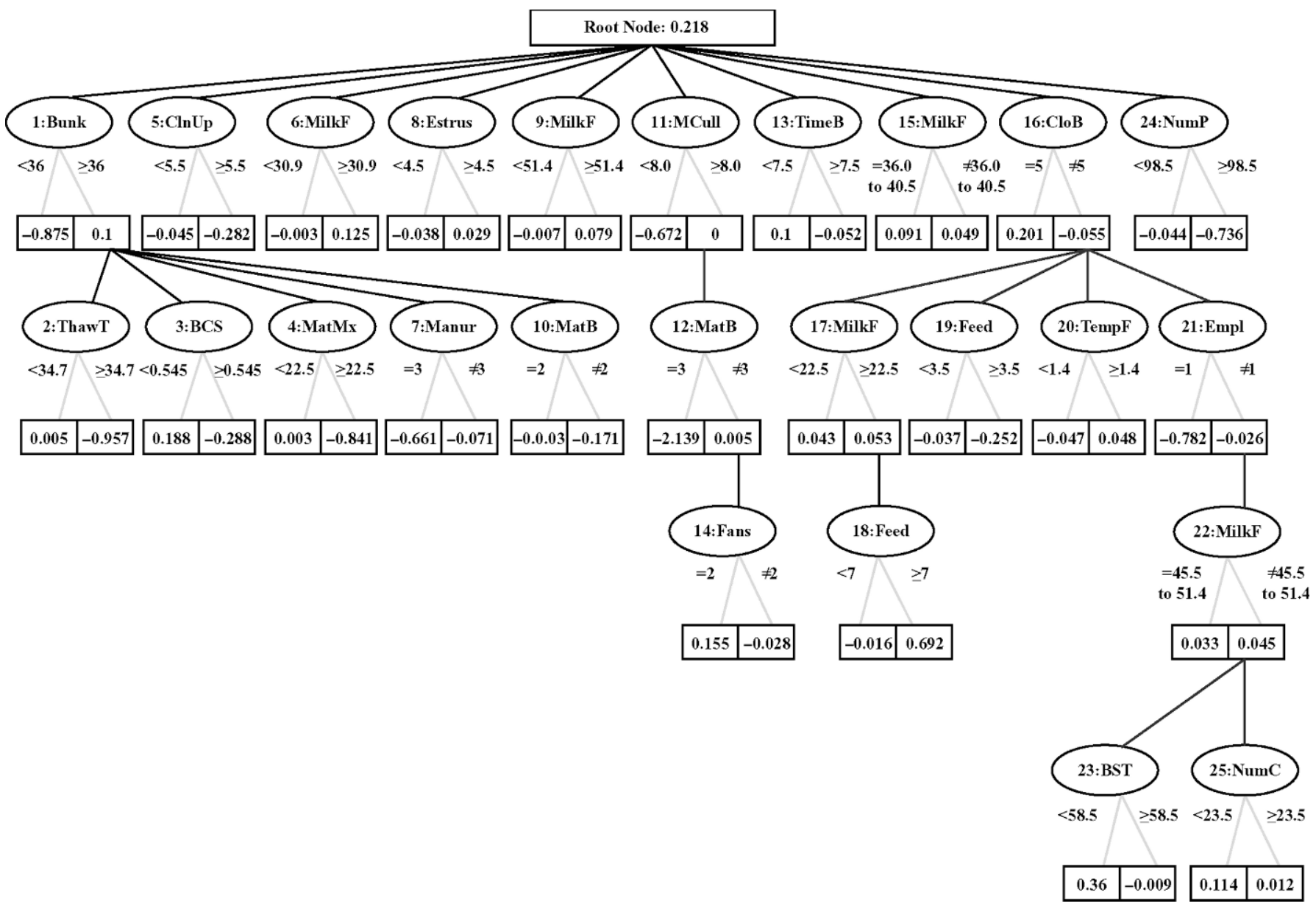

Figure 2. Alternating decision tree classifier for explaining pregnancy status at 150 DIM. Decision nodes are represented by an oval structure, and each contains a number (in bold font) that indicates the iteration at which that node was added to the tree, followed by the code assigned to that variable. Cut points are shown along the connectors between decision nodes and the prediction nodes ("a" and "b"), in which the latter are represented by rectangular structures and contain the corresponding prediction values.

to semen-handling techniques, specifically the temperature at which straws of frozen semen were thawed before AI. The alternating decision tree algorithm selected a temperature of $34.7^{\circ} \mathrm{C}$ as the cut point, and among herds that had $>36 \mathrm{~cm}$ of bunk space per cow, the subset of herds that routinely thawed semen at temperatures greater than $34.7^{\circ} \mathrm{C}$ had a lesser probability of pregnancy by 150 DIM (prediction node "b" value of -0.957). The relationship between semen thawing temperature and probability of pregnancy decreased curvilinearly (Figure 3), but relatively few herds in this branch of the tree ( 3 herds $<34.7^{\circ} \mathrm{C}$ and 4 herds $\geq 34.7^{\circ} \mathrm{C}$ ) provided information about semen thawing temperature in the herd management survey. Others (Kaproth et al., 2002) have addressed the importance of thawing temperature and technique on subsequent conception rates.

Node 3, which was also a child of prediction node "b" at node 1 , corresponded to the percentage of BCS faults in each herd. A fault was assigned for each individual cow whose BCS was below a predetermined threshold for a given number of days postpartum at the time of measurement (Caraviello, 2005). These BCS thresholds were $3.0,2.5$, and 2.75 for cows that were -60 to 30,31 to 180 , and $>180$ d postpartum, respectively. Among the 63 herds in the Upper Midwest that were evaluated for BCS from May to August, 2004, herds in which $\geq 54.5 \%$ of cows had BCS faults generated a prediction node "b" value of -0.288 , indicating a smaller probability of pregnancy by 150 DIM. Figure 3 also shows a negative relationship between the percentage of BCS faults and the probability of pregnancy by 150 DIM, especially when the percentage of BCS faults is large. Although the actual BCS of a cow being inseminated would be more informative than the percentage of BCS faults in the herd in which she resides, the latter can be scored quickly and efficiently in a single (perhaps 
Table 3. Variables included in the alternating decision tree for pregnancy status at 150 DIM, as shown in Figure 2, ordered by the sequence in which they were added to the tree, along with corresponding cut points and prediction values ${ }^{1}$

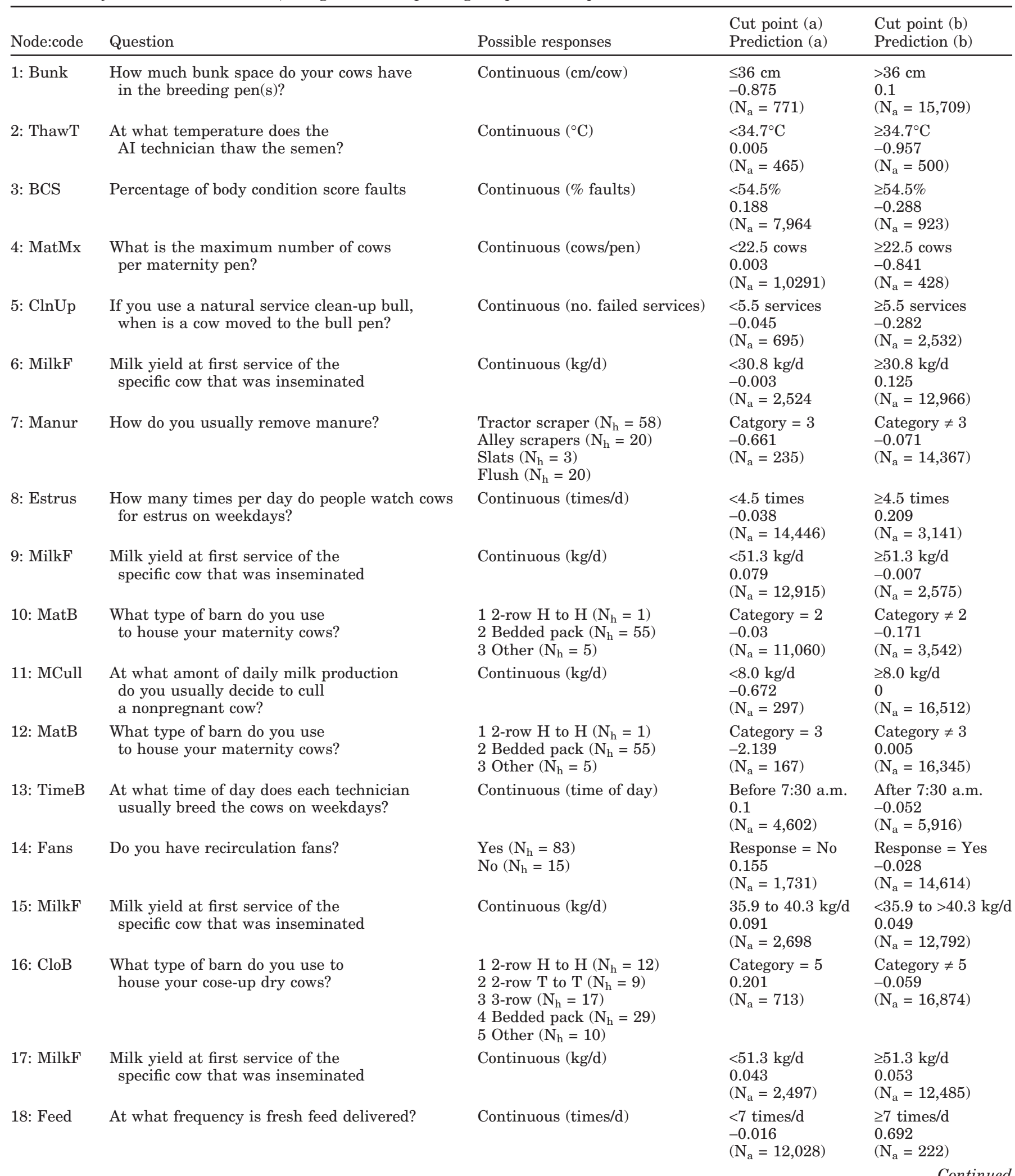


Table 3 (Continued). Variables included in the alternating decision tree for pregnancy status at 150 DIM, as shown in Figure 2, ordered by the sequence in which they were added to the tree, along with corresponding cut points and prediction values ${ }^{1}$

\begin{tabular}{|c|c|c|c|c|}
\hline Node code & Question & Possible responses & $\begin{array}{l}\text { Cut point (a) } \\
\text { Prediction (a) }\end{array}$ & $\begin{array}{l}\text { Cut point (b) } \\
\text { Prediction (b) }\end{array}$ \\
\hline 19: Feed & At what frequency is fresh feed delivered? & Continuous (times/d) & $\begin{array}{l}<3.5 \text { times } / \mathrm{d} \\
-0.037 \\
\left(\mathrm{~N}_{\mathrm{a}}=15,693\right)\end{array}$ & $\begin{array}{l}\geq 3.5 \text { times } / \mathrm{d} \\
-0.252 \\
\left(\mathrm{~N}_{\mathrm{a}}=917\right)\end{array}$ \\
\hline 20: TempF & $\begin{array}{l}\text { Outside temperature on the specific day } \\
\text { of first service on which the cow } \\
\text { was inseminated }\end{array}$ & Continuous $\left({ }^{\circ} \mathrm{C}\right)$ & $\begin{array}{l}<1.4^{\circ} \mathrm{C} \\
-0.047 \\
\left(\mathrm{~N}_{\mathrm{a}}=2,651\right)\end{array}$ & $\begin{array}{l}\geq 1.4^{\circ} \mathrm{C} \\
0.048 \\
\left(\mathrm{~N}_{\mathrm{a}}=12,357\right)\end{array}$ \\
\hline 22: MilkF & $\begin{array}{l}\text { Milk yield at first service of the } \\
\text { specific cow that was inseminated }\end{array}$ & Continuous $(\mathrm{kg} / \mathrm{d})$ & $\begin{array}{l}45.3 \text { to } 51.3 \mathrm{~kg} / \mathrm{d} \\
0.033 \\
\left(\mathrm{~N}_{\mathrm{a}}=2,503\right)\end{array}$ & $\begin{array}{l}<45.3 \text { to } 51.3 \mathrm{~kg} / \mathrm{d} \\
0.045 \\
\left(\mathrm{~N}_{\mathrm{a}}=12,444\right)\end{array}$ \\
\hline 25: NumC & $\begin{array}{l}\text { What is the average number of cows } \\
\text { in the close-up dry cow pen? }\end{array}$ & Average number of cows in the pen & $\begin{array}{l}<23.5 \text { cows } \\
0.114 \\
\left(\mathrm{~N}_{\mathrm{a}}=3,367\right)\end{array}$ & $\begin{array}{l}\geq 23.5 \text { cows } \\
0.012 \\
\left(\mathrm{~N}_{\mathrm{a}}=7,466\right)\end{array}$ \\
\hline
\end{tabular}

${ }^{1}$ For discrete variables, $\mathrm{N}_{\mathrm{h}}$ indicates the number of herds in that category, For all variables, $\mathrm{N}_{\mathrm{a}}$ indicates the number of individual cow records reaching that prediction node.

annual) visit to the farm. Studies (Royal et al., 2002) have evaluated the impact of BCS on fertility, and it is well known that cows with lesser BCS in early lactation or that have larger BCS changes during lactation have impaired reproductive performance. Larger BCS are genetically correlated with improved reproductive performance (Dechow et al., 2001), whereas smaller BCS are associated with increased time from parturition to onset of ovarian activity (Royal et al., 2002).

Node 4 , which reflected the maximum number of cows per maternity pen (mean entry and exit times for maternity pens were $2 \mathrm{~d}$ prepartum and $1 \mathrm{~d}$ postpartum, respectively), was also a child of prediction node " $\mathrm{b}$ " at node 1 . The value of prediction node " $\mathrm{b}$ " at node 4 , -0.841 , indicates a smaller probability of pregnancy by 150 DIM for cows in herds that allowed $>22.5$ cows per maternity pen, but only 2 herds in this branch of the tree (428 total cows) allowed such high stocking of maternity pens. As shown in Figure 3, the probability of pregnancy by 150 DIM appeared to decrease more or less linearly as the maximum number of cows per maternity pen increased from roughly 10 to 25 . Weigel et al. (2003) reported an association between involuntary culling rates and the presence or absence of individual maternity pens. Grant and Albright (2001) noted that overcrowding, particularly in the absence of sufficient bunk space, can affect cow behavior and feed intake.
Node 5 identified the number of failed services after which a cow is moved to the bull pen for natural service (clean-up) mating as a potential indicator of reproductive efficiency. The cut point for this variable was 5.5 inseminations, and as shown in Figure 3, the probability of pregnancy by 150 DIM seemed to decrease as the number of failed services increased. It is important to note, however, that this variable was only applicable to herds that routinely used a clean-up bull, and herds that used $100 \%$ AI did not reach this decision node (the data included 6 herds with $<5.5$ services and 11 herds with $\geq 5.5$ services). Also note that both prediction nodes were negative, which indicates poorer reproductive performance in herds that use clean-up bulls, compared with herds using $100 \%$ AI. Overton (2005) reported that natural service mating costs approximately $\$ 10$ more per cow than when using an AI program. De Vries et al. (2005b) reported slightly greater pregnancy rates among natural service and mixed AI and natural service herds, compared with $100 \%$ AI herds, during the summer, although pregnancy rates for all 3 groups were similar during the winter. Furthermore, natural service and mixed herds sacrificed 1,333 and $337 \mathrm{~kg}$ of rolling herd average milk, respectively. Smith et al. (2004) noted that herds that used a combination of $\mathrm{AI}$ and natural service had longer calving intervals and more days dry than herds that used 100\% AI. 

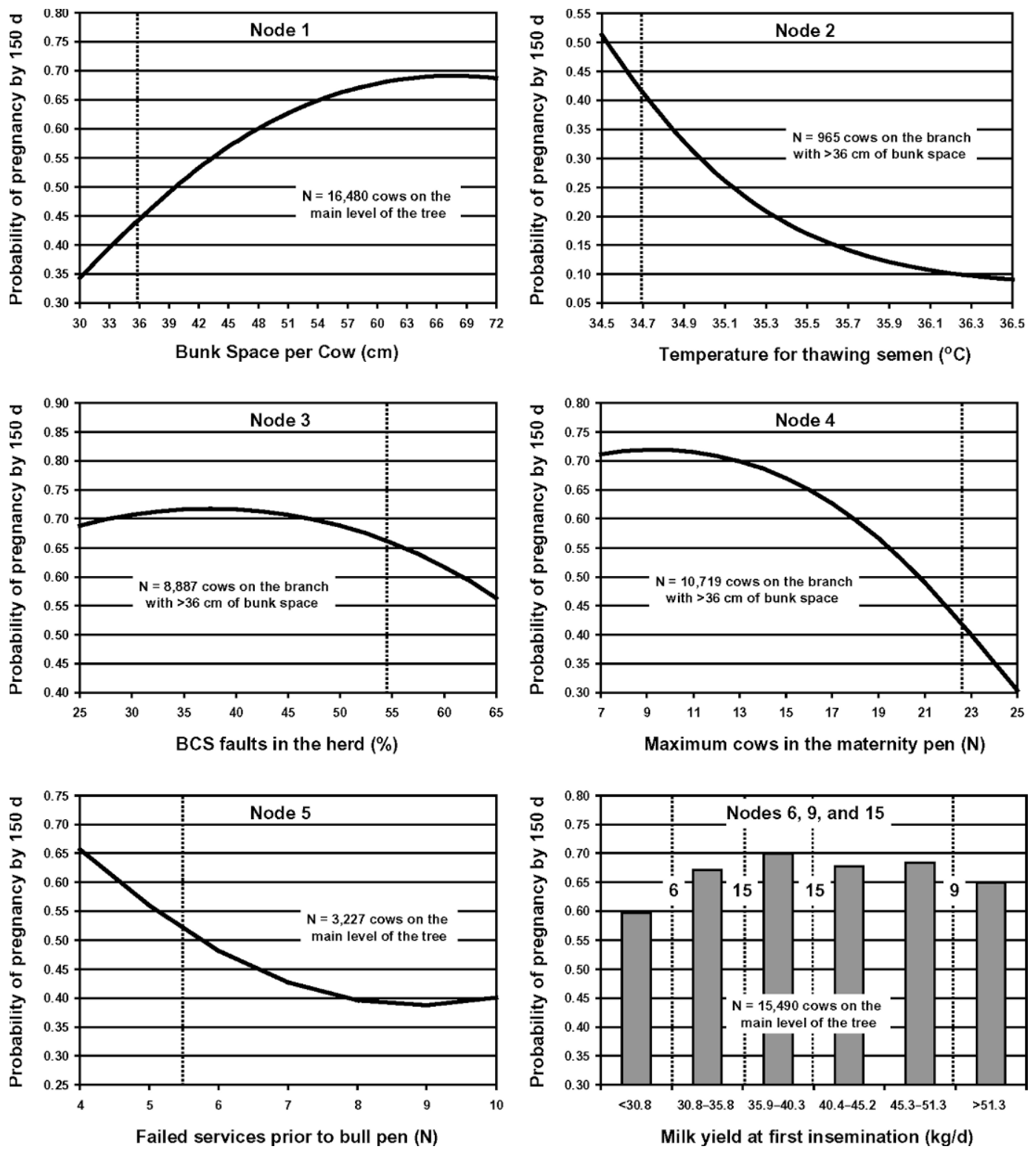

Figure 3. Predicted percentage of cows pregnant by 150 DIM, based on logistic regression of pregnancy status on each explanatory variable without controlling for other factors, according to bunk space per cow in the breeding pens (node 1), temperature for thawing frozen semen (node 2), percentage of BCS faults in the hed (node 3), maximum number of cows in the maternity pen (node 4), maximum number of failed services before moving a cow to the bull pen (node 5), and daily milk yield of the cow at first AI (nodes 6,9, and 15). Vertical dotted lines represent cut points for the corresponding decision nodes (lines are numbered to match the decision nodes, when applicable).

Nodes 6, 9, and 15 were all functions of daily milk yield of a specific cow on (or near) the date of first insemination. Because all 3 of these decision nodes were located at the main level of the tree (i.e., they were children of the root node), the nodes were combined into 1 logistic regression (Figure 3). Furthermore, because of the tendency of the decision tree algorithm to isolate individual cows with extreme daily milk yields, this variable was categorized into 6 levels. The cut points for decision nodes 6 and 9 were $<30.8$ and $>51.3 \mathrm{~kg} /$ d, respectively, whereas decision node 15 isolated the category of cows with daily milk yield between 35.9 and $40.3 \mathrm{~kg} / \mathrm{d}$. As indicated by the negative value for prediction node "a" at decision node 6 , cows with daily production $<30.8 \mathrm{~kg} / \mathrm{d}$ seemed to have a smaller probability of pregnancy by 150 DIM than their contemporaries, and the poorer production of these cows might indicate the presence of clinical or subclinical illness. On the other hand, the prediction node "b" value at decision node 9 was also negative, indicating a reduced probabil- 
ity of pregnancy by 150 DIM for cows with daily milk yield $>51.3 \mathrm{~kg} / \mathrm{d}$. As shown in Figure 3, the greatest probability of pregnancy occurred among cows milking from 35.9 to $40.3 \mathrm{~kg} / \mathrm{d}$, and this category was isolated by decision node 15 . Nodes 17 and 22 also differentiated cows based on milk yield at first AI, but these decision nodes were located deep within the tree, as children of node 16 and nodes 16 and 21, respectively. The flexibility of the alternating decision tree algorithm is demonstrated by its ability to include a single explanatory variable, such as milk yield at first service, multiple times at different levels of the tree and with different cut points. Westwood et al. (2002) observed that cows producing more than $38 \mathrm{~kg} / \mathrm{d}$ were 2.6 times more likely to ovulate later in lactation than cows producing less than $29 \mathrm{~kg} / \mathrm{d}$. They also observed that cows whose first ovulation occurred after 53 DIM had a 1.6-fold greater risk of an increased interval from calving to first breeding when compared with cows that ovulated before 21 DIM. Similarly, Weigel (2004) showed that primiparous cows with milk production $>36 \mathrm{~kg} / \mathrm{d}$ and multiparous cows with milk production $>45 \mathrm{~kg} / \mathrm{d}$ had 1.8 and $1.6 \%$ lower conception rates, respectively, when compared with other cows of the same age.

Node 7, which reflects the type of manure removal system, was also child of prediction node "b" at decision node 1 . As indicated by the negative prediction node value in Table 3 , as well as the relationships shown in Figure 4, herds that used a slatted floor for manure removal appeared to have fewer pregnant cows by 150 DIM. It is important to note that very few herds were represented in this category. Bewley et al. (2001) reviewed the costs and benefits of various barn designs, manure removal systems, and related management issues.

Node 8 was a function of the number of times cows were observed for heat each day. Herds $(n=14)$ in which cows were watched more than the cut point of 4.5 times/d appeared to have greater percentages of pregnant cows by 150 DIM than herds $(n=57)$ in which cows were watched $<4.5$ times/d, as indicated by Figure 4 and the prediction node value shown in Table 3 . Although extensive use of timed AI programs could eliminate the need for detection of estrus, only 2 herds reported that cows were not watched for estrus at least once daily. This variable cannot separate herdsmen that are specifically watching cows for estrus from those that are "multitasking" this activity and several others simultaneously. Estrus-detection efficiency is a key factor of reproductive success, as noted by Donovan et al. (2003) and Gröhn and Rajala-Schultz (2000), and a vast number of estrus-detection aids have been proposed (Saumande, 2002).
Nodes 10 and 12 reflected the type of maternity housing provided for cows. Node 10 was a child of node 1 (bunk space per cow) and node 12 was a child of node 11 (amount of daily milk yield at which nonpregnant cows are destined to be culled). Node 10 indicated that herds with a bedded pack had greater reproductive efficiency, compared with herds that used 2-row head-tohead free stalls or other housing systems. Node 12 further isolated herds in the "other" category (i.e., not a bedded pack or 2-row head-to-head free stalls) as having smaller percentages of pregnant cows by 150 DIM. Relationships corresponding to these nodes are similar, as shown in Figure 4, although the effect of the "other" category was not estimable in the generalized linear model analysis because of few herds (and records) reaching prediction node "a" of decision node 12.

Decision node 11 was a function of the amount of daily milk production at which each herd manager decides to cull nonpregnant cows. Although the value of -0.672 at prediction node "a" reflected data from only 1 herd, the relationship shown in Figure 4 shows that the percentage of cows pregnant by 150 DIM appeared to be greater in herds that had more stringent culling criteria for poorer-producing, nonpregnant cows. This is not surprising, because herds with greater overall reproductive efficiency tend to have shorter average DIM and a larger supply of replacement heifers, so they can afford to have more stringent culling criteria.

Node 13, which was based on the time of day when cows are typically inseminated, indicated a slight advantage in reproductive efficiency among herds $(n=22)$ that bred cows before 7:30 a.m. than herds $(n=32)$ that bred cows later in the day. As indicated by the flat logistic regression curve (Figure 4), the cut point of 7:30 a.m. assigned by the alternating decision tree algorithm may reflect differences in other management or environmental characteristics that were confounded with breeding time, rather than a direct effect of this variable.

Decision node 14, which reflects the presence or absence of cooling fans, must be interpreted cautiously. The prediction node "a" value of 0.155 seems to imply an advantage in reproductive efficiency among herds that do not have fans. A more likely interpretation is that the percentage of cows pregnant by 150 DIM is greater in herds located in cool climates, which in turn do not need cooling fans.

Node 16 was based on the type of barn used to house close-up dry cows. Herds that used a 2- or 3-row freestall barn or a bedded pack appeared to have greater reproductive efficiency than herds that provided some other type of housing system, although relatively few herds were represented in the latter category. As shown in Figure 5, the probability of pregnancy by 150 DIM 


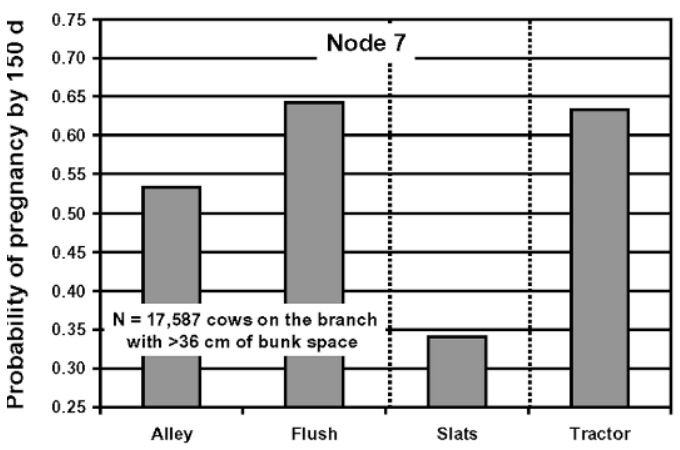

Type of manure removal system

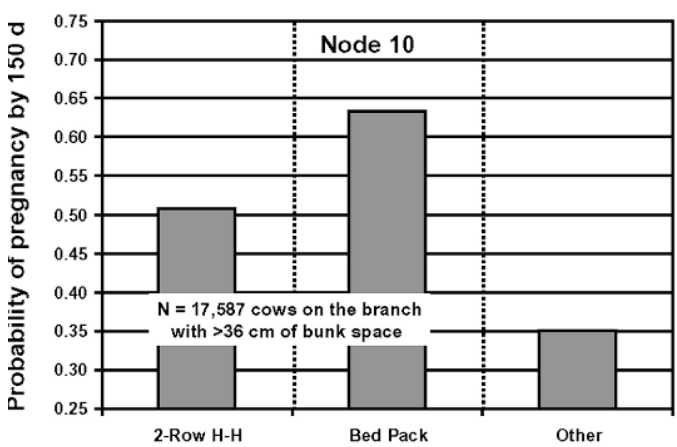

Type of housing for maternity cows

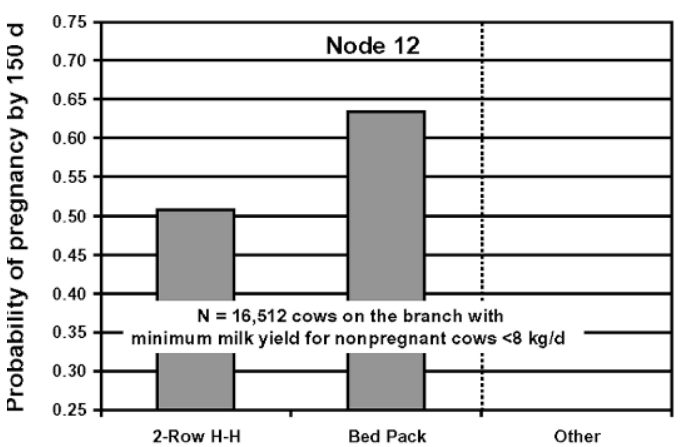

Type of housing for maternity cows
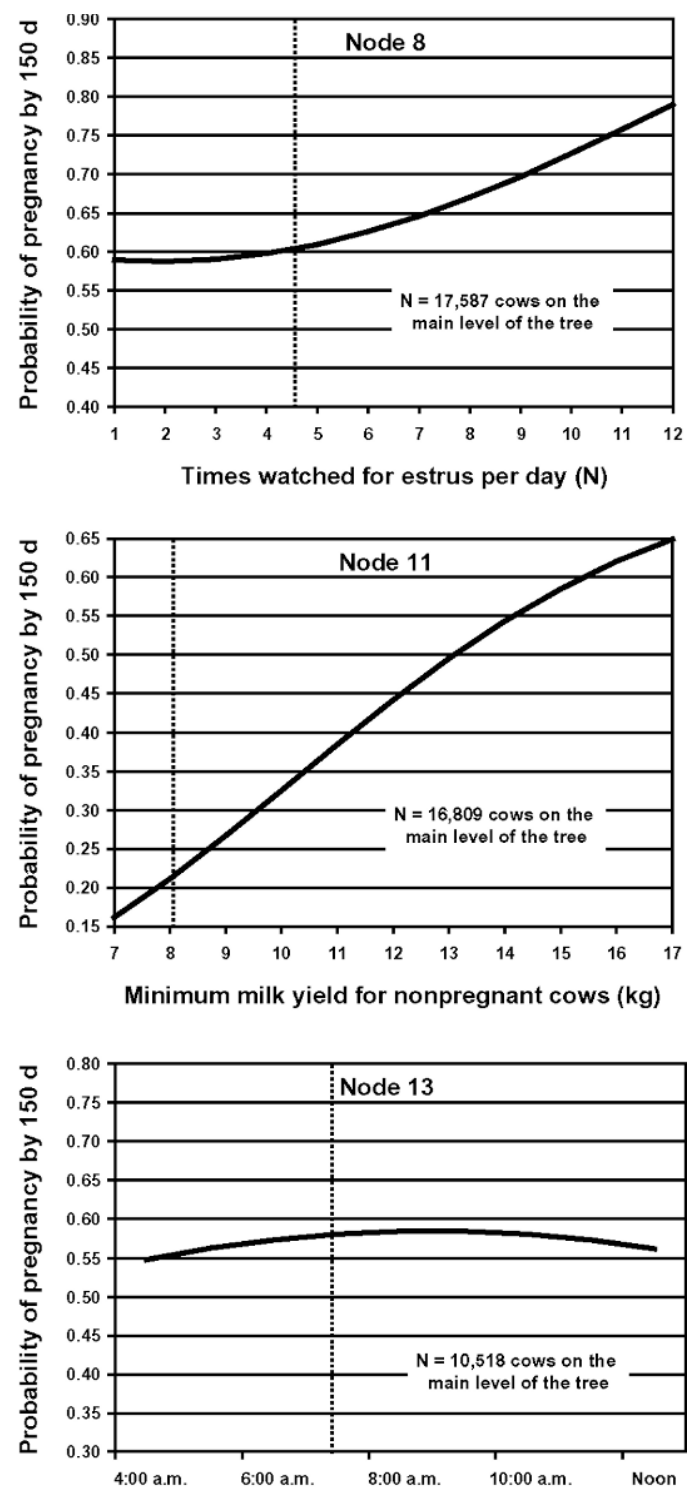

Time of day when cows are inseminated

Figure 4. Predicted percentage of cows pregnant by 150 DIM, based on logistic regression of pregnancy status on each explanatory variable without controlling for other factors, according to the type of manure removal system (node 7), number of times cows are watched for estrus per day (node 8), type of housing for maternity cows (node 10), minimum daily milk yield before deciding to cull a nonpregnant cow (node 11), type of housing for maternity cows (node 12), and time of the day when cows are inseminated (node 13). Vertical dotted lines represent cut points for the corresponding decision nodes.

was greatest in herds with a 2-row head-to-head freestall barn or a bedded pack.

Frequency of feed delivery was identified in node 18, which was a child of nodes 16 (type of close-up dry cow housing) and 17 (daily milk yield at first AI), and node 19 , which was also a child of node 16 . The cut point of 7 times/d chosen by decision node 18 isolated only 1 herd ( 222 cows) in prediction node "b," because the vast majority of 24 herds provided fresh feed once, twice, or three times daily. The logistic regressions shown in
Figure 5 indicate that reproductive efficiency was greatest in herds that fed cows less frequently. De Vries et al. (2005a) reported that increasing the frequency of fresh feed delivery tended to stimulate feeding behavior, improve the NDF content of the TMR, and enhance feed access for subordinate cows.

Node 20, which was a function of maximum outside temperature on the day of $\mathrm{AI}$ at the nearest weather station, had an extremely low cut point of $1.4^{\circ} \mathrm{C}$. Figure 5 indicates a weak relationship between weather sta- 


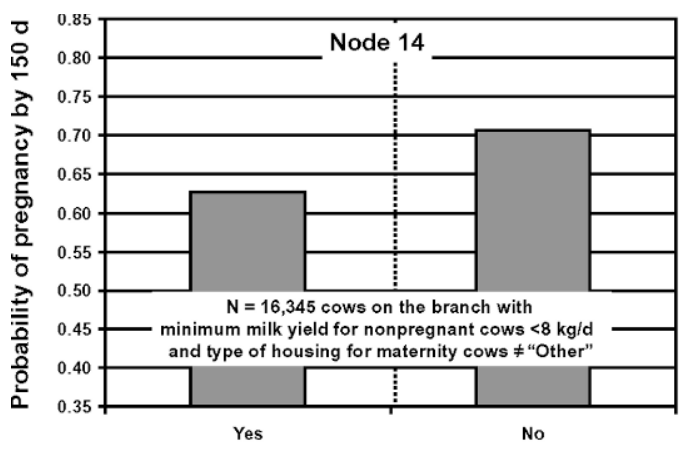

Use of fans for cooling cows
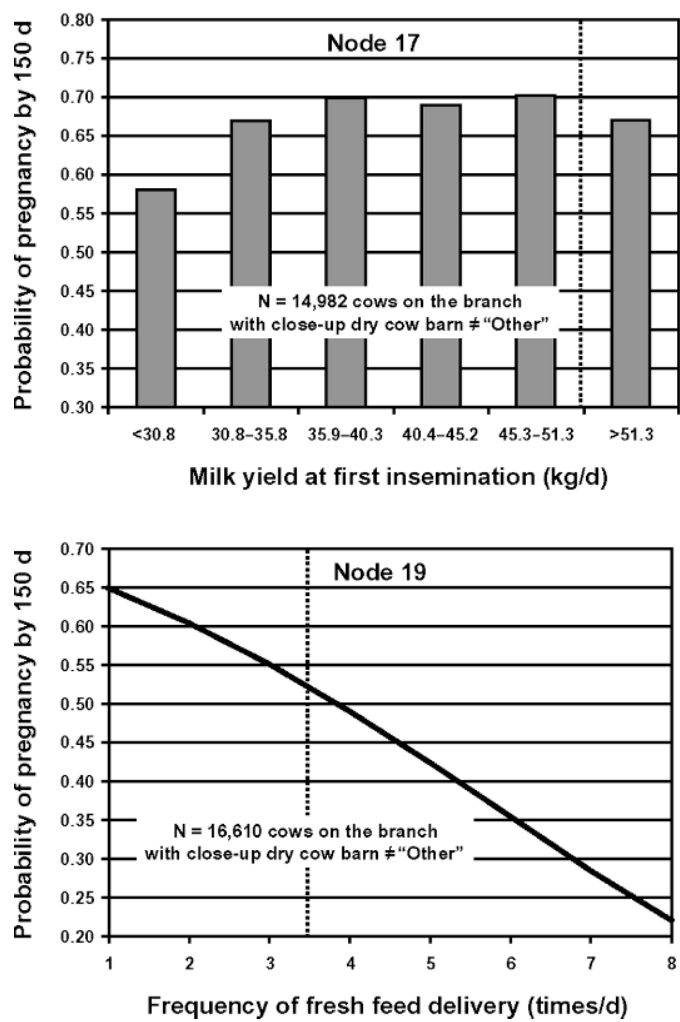

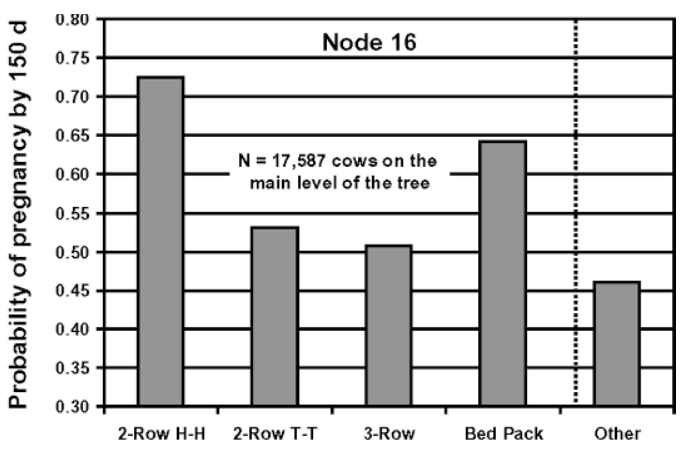

Type of housing for close-up dry cows
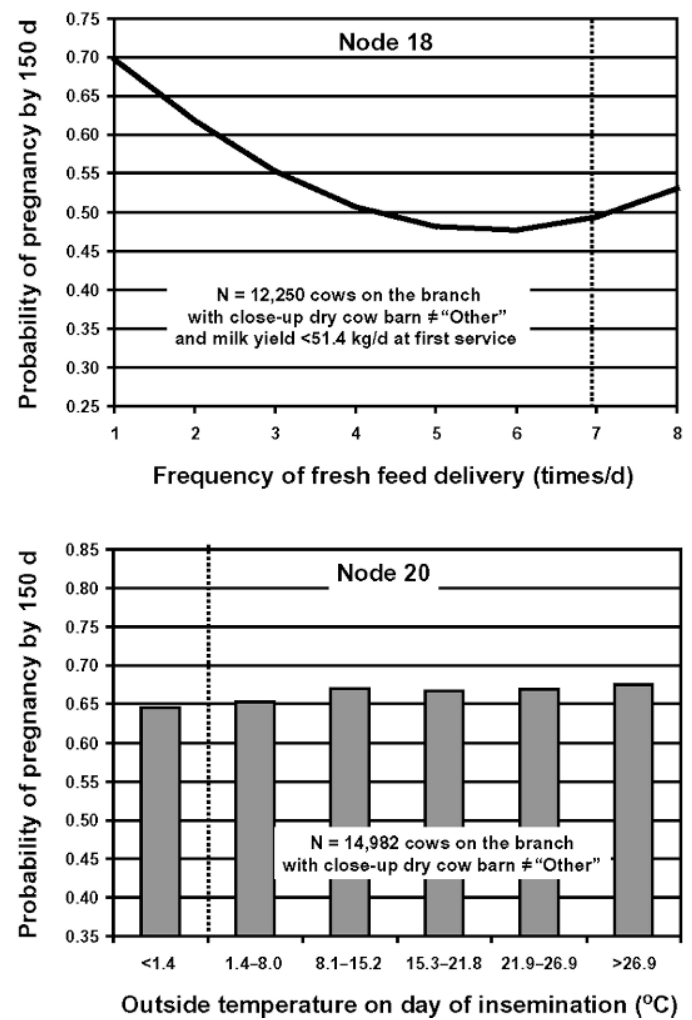

Figure 5. Predicted percentage of cows pregnant by 150 DIM, based on logistic regression of pregnancy status on each explanatory variable without controlling for other factors, according to use of fans for cooling cows (node 14), type of housing for close-up dry cows (node 16), daily milk yield of the cow at first insemination (node 17), frequency of fresh feed delivery (node 18), frequency of fresh feed delivery (node 19), and outside temperature on the day of insemination (node 20). Vertical dotted lines represent cut points for the corresponding decision nodes.

tion temperatures and the probability of pregnancy by 150 DIM. The temperature or THI at a nearby weather station may be a poor indicator of actual conditions within the barn, because the latter can be influenced quite heavily by sprinklers, cooling fans, and other heat abatement devices. Numerous studies have documented the detrimental effects of heat stress on fertility in lactating dairy cows, including decreased feed intake, reduced physical activity, diminished expression of estrus, compromised conception rates, and increased em- bryonic deaths (Sartori et al., 2002). Heat-stressed cows have a reduced proestrous rise in estrogen, smaller size of the second-wave dominant follicle, greater numbers of follicular waves per estrous cycle, and longer luteal phases (Wilson et al., 1998).

Ability to keep good employees, which was scored on a 5 -point ordinal scale, was selected as node 21. Although only 2 herds offered survey replies of " 1 ," indicating that keeping good employees was very difficult, these herds had significantly impaired reproductive efficiency 
(prediction node "a" value of -0.782). The generalized linear model solution corresponding to category 1 was not estimable because of confounding and lack of information. Employee training was previously identified by Sanders (2005) as an essential component of the reproductive management program on commercial dairy farms.

Node 23, which was a child of nodes 16 (type of housing for close-up dry cows), 21 (ability to keep good employees), and 22 (milk yield at first insemination), reflected the postpartum waiting period before administration of bST. The prediction node "a" value of 0.36 , corresponding to herds that initiated bST biweekly injections before 58.5 DIM, seems to contradict the logistic regression in Figure 6. It is important to note that relatively few cows (346 cows in 2 herds) reached this prediction node, as the cut point of $58.5 \mathrm{~d}$ was extremely low. Santos et al. (2004) reported a positive impact of bST on first-service conception rate and reduced early embryonic loss. Silvia et al. (2002) noted that the time of onset of bST did not affect the percentages of multiparous cows pregnant by 150,200 , or 250 DIM, although later supplementation of bST led to slight increases in the percentages of primiparous cows pregnant at 200 and 250 DIM. Judge et al. (1999) noted that administration of bST at 9 wk postpartum had no effect on the percentage of cows remaining nonpregnant at 150 DIM.

Node 24 was based on the number of cows in the postfresh milk withholding pen, which had mean entry and exit times of 1 and $8 \mathrm{~d}$ postpartum, respectively. Two herds that averaged $\geq 98.5$ cows per pen had a smaller percentage of cows pregnant by 150 DIM than 53 herds with fewer cows per pen, as indicated by the prediction node " $b$ " value of -0.736 . Grant and Albright (2001) noted that large groups (>200 cows) are not a problem per se, but overcrowding of pens can reduce feeding activity, alter resting behavior, and decrease rumination.

Node 25, which was nested within nodes 16 (type of barn used to house close-up dry cows), 21 (ability to keep good employees), and 22 (milk yield at first insemination), was a function of the average number of cows in the close-up dry cow pen. The prediction node "a" value of 0.114 seems to contradict the logistic regression shown in Figure 6, although it is once again important to recognize that this decision node was nested deep within the tree.

Despite the ability of the alternating decision tree algorithm to provide relatively readable trees, some of the interactions modeled by this algorithm are complex and cannot be explained readily. When evaluating individual nodes located at deeper levels within the tree, or nodes that entered the tree at later iterations, it is important to recognize that weights corresponding to the records at these nodes may be different from 1 , and that several complex interactions (especially those involving ancestral nodes) may influence the values of specific prediction nodes. In this study, the number of nodes that maximized the predictive ability of the decision trees for first-service conception rate and pregnancy status at 150 DIM was 22 and 25 , respectively, and this was determined via 10 -fold cross-validation in numerous preliminary analyses (Caraviello, 2005). On the other hand, it is likely that a number of larger or smaller decision trees with similar or only slightly poorer predictive ability could have been constructed. Furthermore, it is likely that alternative, correlated variables (either variables that were not measured in this study, or variables that were included in this study but were not selected for the decision trees) could have served as suitable substitutes for the variables identified in the decision trees presented herein. Therefore, decisions regarding the selection of variables to include in decision trees in practice should consider not only the predictive ability of each variable, but also the cost of recording each variable in an experimental or commercial setting.

\section{CONCLUSIONS}

The present study utilized the alternating decision tree algorithm to identify variables affecting first-service conception rate and probability of pregnancy by 150 DIM on large dairy farms, show interactions between these variables, and also build predictive models for these important reproduction traits. This algorithm was able to accommodate a complex data set with multicollinearity problems and more than 300 explanatory variables that were recorded as binary, categorical, or continuous, and that were often missing or not applicable. The tree for first-service conception rate identified maintenance hoof trimming, bedding in the dry cow pen, cow restraint system, and voluntary waiting period as key variables. The most important explanatory variables affecting pregnancy status at 150 DIM were bunk space per cow, temperature for thawing AI semen, percentage of BCS faults within the herd, number of cows per maternity pen, strategy for using clean-up bulls, and milk yield at first AI. The alternating decision tree algorithm provided greater predictive ability for status at 150 DIM than for first-service conception rate, as measured by 10 -fold cross-validation, and this seems to indicate that pregnancy status at 150 DIM is a more robust measure of the overall reproductive performance of a commercial dairy farm than first-service conception rate.

Future studies can use similar machine-learning methods to analyze a smaller, more focused set of ex- 

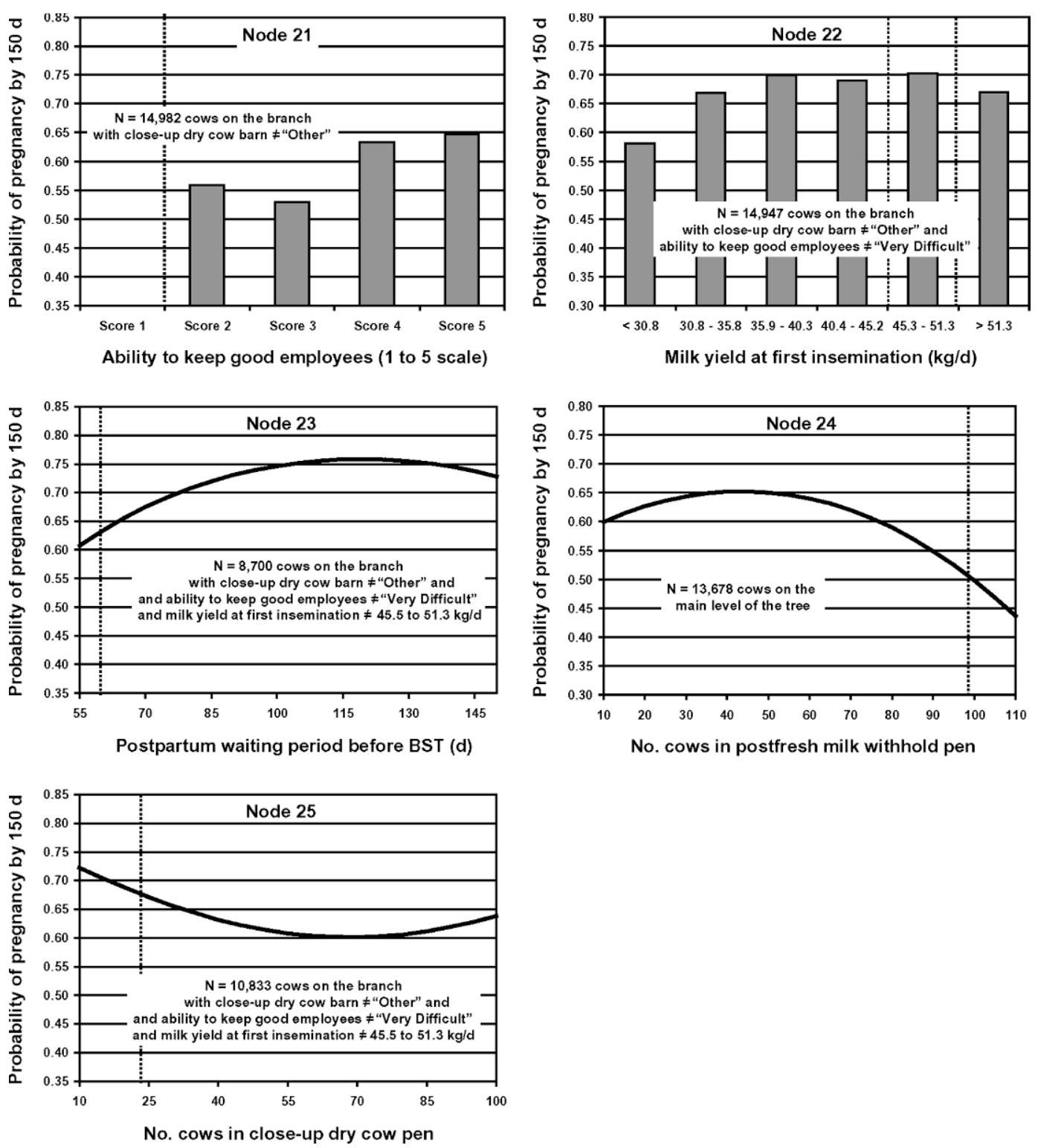

Figure 6. Predicted percentage of cows pregnant by 150 DIM, based on logistic regression of pregnancy status on each explanatory variable without controlling for other factors, according to the ability to keep good employees (node 21), daily milk yield of the cow at first insemination (node 22), length of the postpartum waiting period before bST (node 23), average number of cows in the postfresh milk withhold pen (node 24), and average number of cows in the close-up dry cow pen (node 25). Vertical dotted lines represent cut points for the corresponding decision nodes.

planatory variables than the large field data set examined herein. In addition, when the main goal is to understand interactions between explanatory variables instead of building the best possible predictive model, consideration should be given to coding strategies that can minimize the incidence of extreme cut points that tend to isolate records from a few selected cows or herds. Thresholds different from zero have the potential to meet different needs (e.g., in situations in which a falsepositive error is more costly than a false-negative error) and should be considered in future studies through further exploring receiver operating characteristic curves and cost-sensitive classification. Furthermore, classification of records into multiple categories based on confidence level (i.e., the classification margin) could prove interesting in field applications; for example, one might be able to identify cows for which a particular management intervention is warranted.

This alternating decision tree algorithm can be implemented using public domain software, and because of 
its computational efficiency, it is suitable for routine field applications by veterinarians, nutritionists, or reproductive consultants using a standard laptop computer. Overall, it seems that advances in computing power, coupled with the availability of efficient, flexible, and user-friendly software, will greatly foster the application of machine learning algorithms in future analyses of reproductive performance and other aspects of dairy herd management in the future.

\section{ACKNOWLEDGMENTS}

The authors thank Alta Genetics (Watertown, WI) for providing data, financial support, and staff time to this project. The cooperation by managers of herds participating in the Alta Genetics Advantage Program is also gratefully acknowledged. The authors also gratefully acknowledge support provided by the Louis and Elsa Thomsen Wisconsin Distinguished Graduate Fellowship. Last, the authors thank the scientists involved in the development of the Weka software package.

\section{REFERENCES}

Bagnato, A., and P. A. Oltenacu. 1994. Phenotypic evaluation of fertility traits and their association with milk production of Italian Friesian cattle. J. Dairy Sci. 77:874-882.

Barker, A. R., F. N. Schrick, M. J. Lewis, H. H. Dowlen, and S. P. Oliver. 1998. Influence of clinical mastitis during early lactation on reproductive performance in Jersey cows. J. Dairy Sci. 81:1285-1290.

Bewley, J., R. W. Palmer, and D. B. Jackson-Smith. 2001. A comparison of free-stall barns used by modernized Wisconsin dairies. J. Dairy Sci. 84:528-541.

Calamari, L., M. G. Maianti, and L. Stefanini. 2003. Effect of space availability at feed bunk and rest area on metabolic conditions and productive responses in dairy cows. Ital. J. Anim. Sci. 2(Suppl. 1):281-283.

Caraviello, D. Z. 2005. Development and evaluation of models for predicting reproductive performance in large commercial dairy herds. Ph.D. Dissertation. University of Wisconsin, Madison.

Caraviello, D. Z., K. A. Weigel, P. M. Fricke, M. C. Wiltbank, M. J. Florent, N. B. Cook, K. V. Nordlund, N. R. Zwald, and C. M. Rawson. 2006. Survey of management practices on reproductive performance of dairy cattle on large US commercial farms. J. Dairy Sci. 89:4723-4735.

Collick, D. W., W. R. Ward, and H. Dobson. 1989. Associations between types of lameness and fertility. Vet. Rec. 125:103-106.

Cook, N. B. 2003. Prevalence of lameness among dairy cattle in Wisconsin as a function of housing type and stall surface. J. Am. Vet. Med. Assn. 223:1324-1328.

Dechow, C. D., G. W. Rogers, and J. S. Clay. 2001. Heritabilities and correlations among body condition scores, production traits, and reproductive performance. J. Dairy Sci. 84:266-275.

De Vries, T. J., M. A. G. von Keyserlingk, and K. A. Beauchemin. 2005a. Frequency of fresh feed delivery affects the behavior of lactating dairy cows. J. Dairy Sci. 88:3553-3562.

De Vries, A., C. Steenholdt, and C. A. Risco. 2005b. Pregnancy rates and milk production in natural service and artificially inseminated dairy herds in Florida and Georgia. J. Dairy Sci. 88:948956.

De Vries, M. J., and R. F. Veerkamp. 2000. Energy balance of dairy cattle in relation to milk production variables and fertility. J. Dairy Sci. 83:62-69.
Donovan, G. A., F. L. Bennett, and F. S. Springer. 2003. Factors associated with first-service conception rate in artificially inseminated nulliparous Holstein heifers. Theriogenology 60:67-75.

Freund, Y., and L. Mason. 1999. The alternating decision tree learning algorithm. Pages 124-133 in Proc. 16th Intl. Conf. on Machine Learning, Bled, Slovenia. Morgan Kaufmann, San Francisco, CA.

Freund, Y., and R. E. Schapire. 1996. Experiments with a new boosting algorithm. Pages 148-156 in Proc. 13th Intl. Conf. on Machine Learning, Bari, Italy. Morgan Kaufmann, San Francisco, CA.

Garbarino, E. J., J. A. Hernandez, J. K. Shearer, C. A. Risco, and W. W. Thatcher. 2004. Effect of lameness on ovarian activity in postpartum Holstein cows. J. Dairy Sci. 87:4123-4131.

Goff, J. P., and R. L. Horst. 1997. Physiological changes at parturition and their relationship to metabolic disorders. J. Dairy Sci. 80:1260-1268.

Grant, R. J., and J. L. Albright. 2001. Effect of animal grouping on feeding behavior and intake of dairy cattle. J. Dairy Sci. 84(E. Suppl.):E156-E163.

Gröhn, Y. T., and P. J. Rajala-Schultz. 2000. Epidemiology of reproductive performance in dairy cows. Anim. Reprod. Sci. 6061:605-614.

Judge, L. J., P. C. Bartlett, J. W. Lloyd, and R. J. Erskine. 1999. Recombinant bovine somatotropin: Association with reproductive performance in dairy cows. Theriogenology 52:481-496.

Kaproth, M. T., J. E. Parks, G. C. Grambo, H. E. Rycroft, J. A. Hertl, and Y. T. Gröhn. 2002. Effect of preparing and loading multiple insemination guns on conception rate in two large commercial dairy herds. Theriogenology 57:909-921.

LeBlanc, S. J., T. F. Duffield, K. E. Leslie, K. G. Bateman, G. P. Keefe, J. S. Walton, and W. H. Johnson. 2002. Defining and diagnosing postpartum clinical endometritis and its impact on reproductive performance in dairy cows. J. Dairy Sci. 85:2223-2236.

Loeffler, S. H., M. J. deVries, and Y. H. Schukken. 1999. The effects of time of disease occurrence, milk yield, and body condition on fertility of dairy cows. J. Dairy Sci. 82:2589-2604.

Lucy, M. C. 2001. Reproductive loss in high-producing dairy cattle: Where will it end? J. Dairy Sci. 84:1277-1293.

Manske, T., J. Hultgren, and C. Bergsten. 2002. The effect of claw trimming on the hoof health of Swedish dairy cattle. Prev. Vet. Med. 54:113-129.

Overton, M. W. 2005. Cost comparison of natural service sires and artificial insemination for dairy cattle reproductive management. Theriogenology 64:589-602.

Pietersma, D., R. Lacroix, and K. M. Wade. 1998. A framework for the development of computerized management and control systems for use in dairy farming. J. Dairy Sci. 81:2962-2972.

Pursley, J. R., M. R. Kosorok, and M. C. Wiltbank. 1997. Reproductive management of lactating dairy cows using synchronization of ovulation. J. Dairy Sci. 80:301-306.

Ravagnolo, O., and I. Misztal. 2002. Effect of heat stress on nonreturn rate in Holsteins: Fixed model analyses. J. Dairy Sci. 85:31013106.

Royal, M. D., J. E. Pryce, J. A. Woolliams, and A. P. Flint. 2002. The genetic relationship between commencement of luteal activity and calving interval, body condition score, production, and linear type traits in Holstein-Friesian dairy cattle. J. Dairy Sci. 85:3071-3080.

Sanders, D. E. 2005. Troubleshooting poor reproductive performance in large herds. Food Anim. Pract. 21:289-304.

Santos, J. E. P., S. O. Luchem, R. L. A. Cerri, K. N. Galvao, R. C. Chebel, W. W. Thatcher, C. S. Dei, and C. R. Bilby. 2004. Effect of $\mathrm{bST}$ and reproductive management on reproductive performance of Holstein dairy cows. J. Dairy Sci. 87:868-881.

Sartori, R., R. Sartor-Bergfelt, S. A. Mertens, J. N. Guenther, J. J. Parrish, and M. C. Wiltbank. 2002. Fertilization and early embryonic development in heifers and lactating cows in summer and lactating and dry cows in winter. J. Dairy Sci. 85:2803-2812.

Saumande, J. 2002. Electronic detection of oestrus in postpartum dairy cows: Efficiency and accuracy of the DEC (showheat) system. Livest. Prod. Sci. 77:265-271.

Sheldon, I. M., D. E. Noakes, A. N. Rycroft, D. U. Pfeiffer, and H. Dobson. 2002. Influence of uterine bacterial contamination after 
parturition on ovarian dominant follicle selection and follicle growth and function in cattle. Reproduction 123:837-845.

Silvia, W. J., R. W. Hemken, and T. B. Hatler. 2002. Timing of onset of somatotropin supplementation on reproductive performance in dairy cows. J. Dairy Sci. 85:384-389.

Smith, J. W., L. O. Ely, W. D. Gilson, and W. M. Graves. 2004. Effects of artificial insemination vs. natural service breeding on production and reproduction parameters in dairy herds. Prof. Anim. Sci. 20:185-190.

Stahl, T. J., B. J. Conlin, A. J. Seykora, and G. R. Steuernagel. 1999. Characteristics of Minnesota dairy farms that significantly increased milk production from 1989-1993. J. Dairy Sci. $82: 45-51$.

Washburn, S. P., W. J. Silvia, C. H. Brown, B. T. McDaniel, and A. J. McAllister. 2002. Trends in reproductive performance in southeastern Holstein and Jersey DHI herds. J. Dairy Sci. 85:244-251.

Weigel, K. A. 2004. Improving the reproductive efficiency of dairy cattle through genetic selection. J. Dairy Sci. 87(E. Suppl.):E86-E92.
Weigel, K. A., R. W. Palmer, and D. Z. Caraviello. 2003. Investigation of factors affecting voluntary and involuntary culling in expanding herds in Wisconsin using survival analysis. J. Dairy Sci. 86:1482-1486.

Westwood, C. T., I. J. Lean, and J. K. Garvin. 2002. Factors influencing fertility of Holstein dairy cows: A multivariate description. J. Dairy Sci. 85:3225-3237.

Wilson, S. J., R. S. Marion, J. N. Spain, D. E. Spiers, D. H. Keisler, and M. C. Lucy. 1998. Effects of controlled heat stress on ovarian function of dairy cattle. 1. Lactating cows. J. Dairy Sci. 81:2124-2131.

Windig, J. J., M. P. L. Calus, and R. F. Veerkamp. 2005. Influence of herd environment on health and fertility and their relationship with milk production. J. Dairy Sci. 88:335-347.

Witten, I. H., and E. Frank. 2000. Data Mining: Practical Machine Learning Tools with Java Implementations. Morgan Kaufmann, San Francisco, CA.

Zdanowicz, M., J. A. Shelford, C. B. Tucker, D. M. Weary, and M. A. G. von Keyserlingk. 2004. Bacterial populations on teat ends of dairy cows housed in free stalls and bedded with either sand or sawdust. J. Dairy Sci. 87:1694-1701. 